\title{
Definiteness and determinacy
}

\author{
Elizabeth Coppock ${ }^{1}$. David Beaver ${ }^{2}$
}

(C) The Author(s) 2015. This article is published with open access at Springerlink.com

\begin{abstract}
This paper distinguishes between definiteness and determinacy. Definiteness is seen as a morphological category which, in English, marks a (weak) uniqueness presupposition, while determinacy consists in denoting an individual. Definite descriptions are argued to be fundamentally predicative, presupposing uniqueness but not existence, and to acquire existential import through general type-shifting operations that apply not only to definites, but also indefinites and possessives. Through these shifts, argumental definite descriptions may become either determinate (and thus denote an individual) or indeterminate (functioning as an existential quantifier). The latter option is observed in examples like 'Anna didn't give the only invited talk at the conference', which, on its indeterminate reading, implies that there is nothing in the extension of 'only invited talk at the conference'. The paper also offers a resolution of the issue of whether possessives are inherently indefinite or definite, suggesting that, like indefinites, they do not mark definiteness lexically, but like definites, they typically yield determinate readings due to a general preference for the shifting operation that produces them.
\end{abstract}

Keywords Definiteness - Descriptions · Possessives · Predicates · Type-shifting

The appendix is dedicated to Robin Cooper, who once wistfully expressed to the first author a wish that people still did fragments these days.

$\triangle$ David Beaver

dib@utexas.edu

Elizabeth Coppock

eecoppock@gmail.com

1 University of Gothenburg and Swedish Collegium for Advanced Study, Uppsala, Sweden

2 The University of Texas at Austin, Austin, USA 


\section{Typology and meaning shifts}

The most frequent word in English is the definite article the, and the indefinite article $a$ follows closely behind. Some languages mark definiteness more than once per noun phrase. Swedish uses both an article and a suffix, for example, and Hungarian verbs reflect the definiteness of their object. Definiteness-marking might be thought to serve some important purpose in light of such facts, not to mention the attention that the word the has received in the linguistic and philosophical literature. Yet many languages, including Russian, Korean, and Hindi, seem to get along without specialized definiteness markers. Here is an example from Russian:

$$
\begin{aligned}
& \text { Anna čitaet knigu } \\
& \text { Anna is-reading book } \\
& \text { 'Anna is reading a/the book.' }
\end{aligned}
$$

How do they manage? Chierchia (1998) suggests a reasonable answer: In such languages, the work is done by meaning shifts, also known as type-shifts, chosen "depending, presumably, on the context" (p. 360). Partee (1986) described two meaning shifts that can apply to a predicate (the typical denotation of a common noun, a function of type $\langle e, t\rangle)^{1}$ :

- IOTA, which shifts a predicate into the unique satisfier of the predicate, if there is one, and is otherwise undefined

- EX, which shifts a predicate into an existential quantifier

IOTA produces what we will refer to as a determinate interpretation, by which we mean that the resulting nominal denotes an individual (i.e. is of type $e$ ). By contrast, EX produces what we will refer to as an indeterminate interpretation, i.e. an interpretation as an existential quantifier. These interpretations are what some scholars would refer to as 'definite' and 'indefinite', respectively, but it is important that our terminology remain neutral as to whether the interpretations in question correspond to the morphosyntactic category of definiteness in any language. Indeed, and more narrowly, our analysis of English implies that determinacy is not what is contributed by the definite article. $^{2}$

\footnotetext{
${ }^{1}$ EX is called A by Partee, but for reasons that should become clear, the latter name would be confusing in the current paper. Chierchia's (1998) nominalization shift ${ }^{\cap}$, which produces kinds, operates on properties, type $\langle s,\langle e, t\rangle\rangle$, not predicates, type $\langle e, t\rangle$, and we therefore assume that it does not form a paradigm with IOTA or EX.

2 A complicating issue when defining determinacy is that an individual denotation may be indistinguishable in a grammar from a type-raised version of that denotation, at least as regards truth-conditions. To take the best known case, a grammar in which proper names denote individuals may yield derivations with precisely the same truth-conditions as a grammar in which proper names denote certain generalized quantifiers. The generalized quantifiers will of course be properties of properties, and hold of just those properties which the corresponding individual has. We may say that a DP denotation is determinate in a grammar if either (a) it is type $e$, or (b) it is a property of properties $Q$, but the context establishes that there is some individual which has all and only the properties of which $Q$ holds. Löbner (2011) provides an extensive and instructive discussion of the typing of nominals, and talks of some nominals "behav[ing] like an individual term in predicate logic", an idea which he then substantiates with diagnostic tests (to which we return in Sect. 4). Thus one option would be to say that a DP has a determinate denotation if, in Löbner's sense, it behaves like a term.
} 
It may be useful for some readers to note that determinate readings typically coincide with what philosophers would commonly term referential readings. However, we intend the term determinate to include cases where a description is interpreted as having type $e$, but is bound (e.g. the word in every word precedes the word's successor), and such nominals are not appropriately classified as referential. Other descriptions that we would classify as 'determinate' but not 'referential' include cases identified by Mates (1973) where the description seems to contain a bound variable, as in The mother of each girl waved to her. Although Mates (1973) may be right that the definite descriptions in these cases cannot be seen as referential, Glanzberg (2007) shows they can be interpreted as terms of type $e$, or in our terminology, determinate (although such examples do raise a number of puzzling issues). Furthermore, as will be discussed in Sect. 2.2.2, we take fictional entities to be potential determinate denotations, and here it is not clear that reference is being made. The term referential also invokes Donnellan's (1966) distinction between 'referential' and 'attributive' uses of definite descriptions, and although the referential/attributive distinction is similar to our determinate/indeterminate distinction insofar as referential uses carry an existence presupposition and attributive uses do not (Donnellan 1966, p. 289), it is not exactly the distinction we are making. Indeed, on Elbourne's (2012) analysis, which is compatible with ours, both referential and attributive uses are determinate (type $e$ ).

According to Chierchia (1998), the IOTA and EX shifts would be responsible for the two alternative interpretations in Russian descriptions as in (1), but IOTA and EX are not available in English. In English, according to Chierchia, overt definite and indefinite determiners do the work instead.

- the $\rightsquigarrow$ IOTA

- $a \rightsquigarrow \mathrm{EX}$

Chierchia also posits a 'Blocking Principle' which prevents a shift from applying in a language that lexicalizes it. Since IOTA and EX are thought to be lexicalized by the articles the and $a$ respectively, the Blocking Principle prevents these type-shifts from being active in English. This is a quite reasonable initial assessment of the situation, but we argue here that English is more like Russian than one would think at first. We suggest, developing an idea outlined in Coppock and Beaver (2012b), that the and $a$ do not in fact express IOTA and EX, and that instead, definite and indefinite descriptions acquire their existence implications through shifting operations, just as bare nominals in Russian do. ${ }^{3}$ Definite descriptions typically receive determinate interpretations, but they can be interpreted indeterminately as well, as proposed by Coppock and Beaver (2012b). This paper argues more carefully for the proposal, spells it out within a formally precise compositional fragment, and illustrates the generality of the approach by applying it to possessives.

\footnotetext{
3 As discussed below, much of the literature on predicative uses of definite and indefinite descriptions in English takes the property denotation to be derived from underlying individual or quantificational meanings. An exception is Zimmermann (1993), who, like us, takes the property denotation of indefinites to be basic, with the implication that type shifting principles will be needed when indefinites occur in argument positions. His analysis of indefinites as property denoting in certain intensional contexts would presumably be compatible with the analysis of indefinites we give here.
} 
In Sect. 2, we argue that definiteness, at least in English, indicates a uniqueness presupposition, and nothing else-in particular, definiteness-marking does not signal existence. To do this, we first establish the relatively uncontroversial point that definite descriptions have a predicative use (Sect. 2.1). We argue in Sect. 2.2 that clearly predicative uses commonly do not convey existence, and therefore, that an existence presupposition is not lexically encoded by the definite article. The key data comes from anti-uniqueness effects, which can be found in sentences involving exclusives such as (2). (2a) implies that there is exactly one author of Waverley, but the negated variant, (2b), implies that there is more than one author.
a. Scott is the only author of Waverley.
[1 author]
b. Scott is not the only author of Waverley.
[>1 author]

The implication that there are multiple authors (the 'anti-uniqueness effect') conflicts with the assumption that the $F$ presupposes the existence of an $F$. Since there are multiple authors, there is no 'only author'. So there is no existence presupposition. We will argue that the definite article does however contribute a uniqueness presupposition (Sect. 2.3).

In Sect. 2.4, we give an analysis of the under which its predicative use is basic, and it carries a uniqueness presupposition, but no existence presupposition. This proposal accounts for the data in (2), as we show in Sect. 2.5. According to this analysis, the and $a$ both denote identity functions on predicates, differing only with respect to a uniqueness presupposition. This helps to explain the distributional observation that co-occurrence of $a(n)$ with only is highly constrained, as we show in Sect. 2.5.

Having broken existence and uniqueness apart, we put them back together again for argumental descriptions in Sect. 3. We propose that descriptions may in principle be interpreted determinately or indeterminately, depending on whether IOTA or EX applies. Again, key data comes from anti-uniqueness effects, this time with descriptions in argument position:

(3) Anna didn't give the only invited talk.

On one prominent reading of this sentence, it is implied that there were multiple invited talks, hence nothing that satisfies the description 'only invited talk'. We argue that, while argumental definites are typically determinate, they can be indeterminate, for example when they give rise to anti-uniqueness effects. In other words, while definite descriptions are usually interpreted with IOTA, they can be interpreted with EX. Two principles conspire so that definites are typically associated with IOTA and indefinites are typically associated with EX: (i) the indefinite article is blocked by the definite article via Maximize Presupposition (Heim 1991; Schlenker 2012; Percus 2006); and (ii) type-shifting operations resulting in simpler types are preferred (Type Simplicity). The theory of definite descriptions in argument position ends up as mostly Fregean, with a dash of Russell. ${ }^{4}$

\footnotetext{
4 We briefly discuss the accounts of Frege (1892 [reprinted 1948]) and Russell (1905) in Sect. 2.2. A contemporary account which, like Frege's and Russell's, takes uniqueness to be part of the conventional meaning of definites is that of Horn and Abbott (2002). Although Horn and Abbott conclude that uniqueness is a conventional implicature of definites rather than a presupposition, many of their arguments would equally
} 
In Sect. 4, we extend the analysis to possessive noun phrases. We argue that possessives, like definites, can be interpreted determinately or indeterminately, but that they are in a sense mid-way in between definites and indefinites. Like definites, and unlike indefinites, they typically receive determinate readings. But unlike definites, they do not signal a uniqueness presupposition. This constitutes our proposed resolution of the controversy as to whether possessives are inherently definite.

We summarize and consider further research directions in Sect. 5, and then present a fragment for English in the appendix, where English expressions are translated into a partial intensional logic IL3, building on Beaver and Krahmer's (2001) Presuppositional Montague Grammar.

\section{Separating existence and uniqueness}

\subsection{Definites can be predicative}

The first point we would like to establish is that definite descriptions have a predicative use. This is not particularly controversial, although it is often ignored. Here is what Strawson (1950, p. 320) said about them:

[I]f I said, "Napoleon was the greatest French soldier", I should be using the word "Napoleon" to mention a certain individual, but I should not be using the phrase, "the greatest French soldier" to mention an individual, but to say something about an individual I had already mentioned. It would be natural to say that in using this sentence I was talking about Napoleon and that what I was saying about him was that he was the greatest French soldier. But of course I could use the expression, "the greatest French soldier", to mention an individual; for example, by saying: "The greatest French soldier died in exile".

Another way of expressing the idea that predicative definites are used to say something "about someone" rather than to refer to someone is to say that they are of type $\langle e, t\rangle$; they characterize sets of individuals.

Further support for the notion that definites can have $\langle e, t\rangle$-type denotations comes from coordination. As Fara (2001) points out, a definite description can be coordinated with a predicative adjective, but a proper name cannot be:

(4) a. John is tall, handsome and the love of my life.

b. \#The love of my life is tall, handsome, and John.

Footnote 4 continued

support a presuppositional view. Thus their account is more Fregean than Russellian, and in this respect broadly in tune with the current proposal. Horn and Abbott's account is also an important antecedent to the current proposal by virtue of employing a competition-based pragmatic mechanism to produce further inferences. Like our proposal, their account crucially depends on (i) the definite article being informationally stronger than the indefinite article, (ii) this difference consisting only in the presence or absence of a uniqueness requirement, and (iii) the two articles being paradigmatic competitors. Their account differs significantly from ours in other respects, for example in that they do not give predicative readings the same centrality that we do, they assume existence to be built into the lexical meanings of both definites and indefinites, and they do not invoke type-shifting operations. 
This can be explained if proper names cannot ordinarily have type $\langle e, t\rangle$ (pace Elbourne 2005; Matushansky 2008; Fara 2015, among others; see Schoubye 2014 for a more thorough review) but definite descriptions can.

Another difference between definites and proper names is that the former, along with adjectives, indefinites, and possessives, can serve as an argument to verbs like consider and find, while the latter, along with some-indefinites and personal pronouns, cannot (Doron 1983; Partee 1986; Winter 2001).
a. John considers this woman \{competent / a good teacher / the queen of the world / his girlfriend\}.
b. *John considers this woman $\{$ Mary / some particular queen / you $\}$.
a. I found John (to be) \{competent / a good teacher / the best can- didate / my strongest supporter $\}$.
b. I found the best candidate * (to be) $\{$ John / some particular indi- vidual / you .

These facts receive a straightforward explanation under the assumption that such verbs select for predicates of type $\langle e, t\rangle$, and that proper names, specific some-indefinites, and personal pronouns cannot function in this way while adjectives and indefinite, definite and possessive descriptions can.

Further evidence that definite, indefinite, and possessive descriptions can be predicative comes from so-called appositional conjunction (Hoeksema 1988), where a conjoined noun phrase is interpreted as a complex description of a single individual and triggers singular rather than plural agreement on the verb when it is used as the subject. The following examples are from Winter (2001, p. 177ff):

(7) a. A great man and a good father has passed away.

b. My great opponent and the hero of my youth has passed away.

c. A great man and the best magician in New Jersey has passed away.

If the singular verb has were to be replaced by plural have, the two conjuncts would refer to distinct individuals. Proper names do not participate in appositional conjunction, even when they are known to refer to the same person, nor do some-indefinites:

a. Dr. Jekyll and Mr. Hyde have/*has passed away.

b. Some great man and some good father have/*has passed away.

These contrasts can be explained under the assumption that appositional conjunction involves coordination of property-denoting expressions, and that they acquire existential import through a type-shift. Winter (2001, p. 179) analyzes these cases using an existential type-shift based on choice functions, and this treatment is very much in line with the analysis we offer below. ${ }^{5}$

As Winter (2001) notes (especially pp. 173-175), a similar contrast exists in Hebrew (Doron 1983), where the copula is obligatory in equative sentences, with proper names,

\footnotetext{
5 Under the treatment we outline in Sect. 3, the IOTA shift would be expected to be preferred over the EX shift as far as we can see (due to the Type Simplicity principle), and this predicts that a presupposition that there is exactly one satisfier of the conjoined description would be accommodated. It is not clear that this prediction is borne out, so appositional constructions may be a fruitful area for future work.
} 
pronouns, and eize 'some' indefinites, but optional with predicate-denoting expressions including predicative adjectives, prepositional phrases, non-specific indefinites, and, crucially, definites. This follows from the assumption that the copula is optional in Hebrew with expressions of type $\langle e, t\rangle$, and, again, that definites fall into this category along with other typically predicative expressions.

\subsection{No existence presupposition}

\subsubsection{Anti-uniqueness effects}

Now that we have established that definites can be predicative, let us address what predicative definites mean. In (9) are three alternative possible $\langle e, t\rangle$ treatments of a definite description of the form 'the $P$ '. (We will give a more precise formalization later.)

$$
\begin{array}{ll}
\text { a. } & \lambda x \cdot[|P|=1 \wedge P(x)] \\
\text { b. } & \lambda x \cdot\left\{\begin{array}{l}
P(x) \text { if }|P|=1 \\
\text { undefined otherwise }
\end{array}\right. \\
\text { c. } \quad \lambda x \cdot\left\{\begin{array}{l}
P(x) \text { if }|P| \leq 1 \\
\text { undefined otherwise }
\end{array}\right.
\end{array}
$$

Russellian

Fregean

Weak Fregean

The Russellian and Fregean versions come from Winter (2001), who remained neutral as to which was better. Something equivalent to the Russellian variant is advocated by Fara (2001) and we advocate the Weak Fregean alternative here, in agreement with Coppock and Beaver (2012b). Under the Russellian treatment illustrated in (9a), existence and uniqueness (hence cardinality of exactly one) are part of the ordinary at-issue content. The treatment in (9b) is "Fregean" insofar as it says that existence and uniqueness are presupposed, as Frege (1892 [reprinted 1948], p. 223) suggested when he wrote that use of the definite article is "permissible if the predicate applies to one and only one single object." 6 Under the third treatment, which we have labelled "Weak Fregean", uniqueness is presupposed but not existence, so the cardinality can be zero or one.

The Russellian variant is subject to many of the familiar criticisms of Russellian treatments of the definite article. For example, the following examples are not felicitous without heavy stress on the:

(10) \#He's not the ambassador to Spain - there are two.

(11) \#There are two ambassadors to Spain; therefore, he is not the ambassador to Spain.

Heavy stress on the produces a reading that might be described in terms of metalinguistic negation. Without heavy stress, only ordinary negation is available. Under

\footnotetext{
6 Winter (2001) and Coppock and Beaver (2012b) describe this alternative as "Strawsonian", but strictly speaking, this is a misnomer, since Strawson did not consider uniqueness a presupposition of the definite article, as Elbourne (2012) discusses. "Fregean" is also an imperfect label, because Frege thought that definite descriptions were "complex proper names", i.e., expressions of type $e$.
} 
the Russellian analysis, the uniqueness component should be targetable by ordinary negation, but it appears not to be. Furthermore, on the Russellian variant, the would have the same denotation as the only, but the is not interchangeable with the only, as illustrated by the following contrast:

(12) I know that this is at least one of the reasons.

a. \#Is it the reason?

b. Is it the only reason?

Space prevents us from rehearsing the full range of challenges for Russellian accounts, so we defer to prior literature for a fuller discussion of this issue. See in particular (Elbourne 2012, Chap. 4, Sect. 5), which contains a rebuttal of Neale's (1990) defense of Russell based on ideas from Grice (1981). As we are convinced on the basis of such discussions as well as some of the data we discuss here that a Russellian analysis is not viable, we concentrate on the Fregean and Weak Fregean views.

Under the assumption that predicative definites presuppose only uniqueness (as under the Weak Fregean view), (13) is predicted not to introduce a presupposition failure (on a predicative reading).

(13) The greatest French soldier is the king of France.

This sentence is predicted to simply be false. The same prediction is not made for argumental definites. As we will argue later, argumental definites typically carry both existence and uniqueness presuppositions, so (14) is, in contrast, predicted to lack a truth value ${ }^{7}$ :

(14) The king of France is the greatest French soldier.

While the contrast is subtle, our intuitions are in line with this prediction. ${ }^{8}$

Predicative definites containing exclusive adjectives provide stronger evidence that definite descriptions do not presuppose existence. As mentioned in the introduction in connection with (2), (15a) implies that there is one author of Waverley; indeed, that is the point that someone uttering that sentence would be making. But when the sentence is placed into an entailment-canceling environment such as negation as in (15b), a yes/no question as in (15c), or the antecedent of a conditional as in (15d), it is no longer implied that there is only one author of Waverley. In (15b), the most prominent interpretation is that there is more than one author. ${ }^{9}$ Similarly, in the question and conditional contexts (15c) and (15d), there may be multiple authors.

(15) a. Scott is the only author of Waverley.

[1 author]

\footnotetext{
7 The ease by which examples like (14) are judged as false appears to be related to factors having to do with information structure (Lasersohn 1993; von Fintel 2004; Schoubye 2009). We do not feel that (14) falls into the class of empty description sentences that are particularly easy to judge as false, but intuitions may differ on this.

8 The contrast may become clearer in question form. Consider (i) Student: Is the king of France the greatest French soldier? Teacher: No. vs. (ii) Student: Is the greatest French soldier the king of France? Teacher: No. The first seems to commit the teacher to the existence of a king of France more strongly than the second.

9 The copula also has an equative interpretation, with which (15a) means 'Scott is the same person as the author of Waverley'. The anti-uniqueness effects arise on the predicative reading of the copula, with which (15a) means 'Only Scott is an author of Waverley'.
} 

b. Scott is not the only author of Waverley.
[>1 author]
c. Is Scott the only author of Waverley?
$[\geq 1$ author]
d. If Scott is the only author of Waverley, then...
$[\geq 1$ author]

Example (15b) is the one that illustrates 'anti-uniqueness' most strongly, as it really denies uniqueness rather than merely calling it into question as in (15c) and (15d).

At first glance, anti-uniqueness effects might look like a disappearance of the uniqueness property normally associated with definites, as inserting an exclusive into a description of the form the $F$ eliminates the implication that there is a unique $F$. Indeed, for this reason, we will persist in referring to the phenomenon as an 'anti-uniqueness' effect. But what these examples really show is that the existence implication normally associated with definite descriptions may be absent. What it means for $x$ to satisfy the predicate 'only author of Waverley' is that no one other than $x$ is an author of this book. If it has multiple authors, then there is no 'only author of Waverley'. That is to say, there is no $x$ such that no one other than $x$ is an author of Waverley; no such $x$ exists. So if there are multiple authors, then with respect to the predicate:

\section{'author of Waverley'}

existence is satisfied but not uniqueness. But with respect to the predicate that the combines with, namely:

$$
\text { 'only author of Waverley' }
$$

uniqueness is (trivially) satisfied but not existence. This data thus challenges the common assumption that definite descriptions imply existence.

The foregoing observations also militate against treating familiarity as part of the lexically-encoded meaning of the definite article as in, for example, Heim (1982). ${ }^{10}$ There is no familiar discourse referent for an individual that is the only author of Waverley in a sentence like "Scott is not the only author of Waverley." We do not wish to rule out a familiarity-based account of argumental uses of definites, ${ }^{11}$ but the novelty/familiarity distinction does not provide a good basis for analyzing predicative descriptions.

There are other uses of definite descriptions which do not seem to imply existence, such as the following.

You're not the queen of the world.

(17) Seven is not the largest prime number.

\footnotetext{
10 This argument against familiarity being encoded in the lexical meaning of definite articles is, of course, clearest for predicative uses, and provides a general argument against encoding familiarity in the lexical meaning of definite articles only to the extent that a theory is to be preferred in which a single, uniform lexical entry is used in both predicative and argumental cases.

11 As an alternative to the view developed in this paper, it would be worthwhile to consider a novelty/familiarity-based variant of the type-shifting operations that provide definite and indefinite descriptions with their existential import. The obvious approach would be to define an analogue of EX which would introduce a referent (thus the meaning of $a$ ) in e.g. Muskens' (1996) dynamic system, and the analogue of IOTA would select an existing one (thus the standard dynamic meaning for the). Even absent our coercionbased analysis of English, such shifts would provide the natural way to extend dynamic approaches to languages like Russian in which articles are normally absent from NPs. We presented a sketch of such a dynamic analysis at the Going Heim workshop at the University of Connecticut in 2015.
} 
A speaker uttering (16) would not be committed to the existence of any queen of the world, nor would someone uttering (17) be committed to the existence of a largest prime number. But examples like (15b), with adjectival exclusives, constitute particularly striking examples of a missing existence implication because the sentence is actually inconsistent with the existence of a satisfier of the description. This situation arises only under a very special combination of circumstances. Crucial to only's ability to give rise to this effect is the following inference pattern: If $x$ is a $P$, and $x$ is not the only $P$, then that means there is no 'only $P$ '. In other words, failure of one thing (with a certain property) to satisfy the predicate implies that there is no satisfier of the predicate. This inference pattern is hard to replicate with other adjectives. Superlatives, for example, do not exhibit this pattern. The conclusion that there is no largest prime number does not follow directly from premises of the form $x$ is a prime number, and $x$ is not the largest prime number.

If all the examples in which the sentence is inconsistent with the existence of something satisfying the predicate involved only, then one might wonder if it is not some minor collocational effect that can be stipulated away and ignored. But this is a productive phenomenon. It also occurs with other exclusive adjectives, including sole, single, and one, which are roughly synonymous with only, as in the following naturally occurring examples:

(18) Lack of supply is not the sole cause of Britain's housing crisis.

(19) Search engine optimization is not the single thing to think about with regards to search engine ranking.

(20) It is worthwhile to visit Kuala Lumpur to see the future of modern Asia, but it is not the one reason to visit.

Perhaps more persuasively, it also occurs with exclusive, which has a different meaning. (Note that only could not be substituted for exclusive in the following example without a change in meaning.)

(21) Dean Hall doesn't have the exclusive right to open-world multiplayer zombie apocalypse simulators, you know.

This sentence implies that Dean Hall has the right to open-world multiplayer zombie apocalypse simulators, and other people have that right as well, so the exclusive right to them does not exist. (See Coppock and Beaver 2014 for detailed discussion of exclusive in this 'rights-modifying' use.)

In all of these cases, we have a sentence containing a definite description of the form 'the $F$ ', whose truth is incompatible with the existence of something satisfying the description ' $F$ '. Clearly, these sentences do not presuppose the existence of an $F$. This means either that the does not presuppose existence, or that the introduces an existence presupposition which disappears through local accommodation. We will argue against the latter possibility in Sect. 2.2.3. 


\subsubsection{Broad and narrow existence}

We should not go too much further without addressing the question of what exactly we mean by 'existence'. There is at least a colloquial usage of the verb exist which seems to pick out a property that changes over time, and is contingent:

(22) My university email account no longer exists.

(23) If that existed, then I would have heard of it!

Fictional characters like Sherlock Holmes are sometimes argued to exist in some sense despite not being 'actual' or 'concrete' (see Nelson 2012 for an overview). Some would take Sherlock Holmes does not exist to be a true sentence, while arguing that Sherlock Holmes nevertheless has a broader kind of existence which makes it possible to truthfully attribute various properties to him (including non-existence). Let us refer to the kind of existence that is described by the colloquial usage of the verb exists as narrow existence and refer to the kind of existence that is captured by the existential quantifier as broad existence. This is the terminology that Kripke (2011, p. 64) uses to distinguish between the two classes of existence under Meinong's view. We do not mean to endorse Meinongianism to the letter, but we do assume that the quantifiers of our representation language may range over objects of which it can be truthfully said in colloquial English that they do not exist, and in that sense lack narrow existence. ${ }^{12}$

There are uses of definite descriptions that show that the definite article lacks a narrow existence presupposition, and this is nothing new. Recall this famous example discussed by Meinong and Russell:

(24) The golden mountain does not exist.

This sentence is felt to be true, which means that there cannot be any actual golden mountain to which the definite description the golden mountain refers. Here are some more examples that we would place in this category ((25) is adapted from Cooper 1978, (26) is due to Robin Cooper, p.c.; the others are naturally occurring):

(25) Max wanted a train set for Christmas but when he opened his presents, the train set wasn't there.

(26) I forgot to buy the wine.

(27) We cancelled the May meeting.

(28) Captain James Cook finally disproved the existence of the Northwest Passage in 1778.

In all of these cases, there does not seem to be any particular object in actuality that is picked out by the definite description (although intuitively it does seem to be the

12 Cf. footnote 8 in Montague (1974): "If there are individuals that are only possible but not actual, [the domain of individuals] is to contain them; but this is an issue on which it would be unethical for me as a logician (or linguist or grammarian or semanticist, for that matter) to take a stand." 
case that there is an imagined state of affairs in which such an object exists). ${ }^{13}$ So the claim that the definite article lacks an existence presupposition might not seem so surprising. But these cases show only that the lacks a narrow existence presupposition. What we are claiming is something stronger: that the definite article lacks even a broad existence presupposition.

We offer the following test for broad vs. narrow existence: When broad existence fails, individual anaphora (as opposed to kind-anaphora) is not possible. The noun phrases that give rise to anti-uniqueness effects cannot be referred back to with an anaphoric pronoun ${ }^{14}$ :

(29) Sue and Jane both scored goals, so Jane didn't score [the only goal $]_{i}$. \#It $\mathrm{It}_{i}$ wasn't a bicycle-kick, either.

The definite description the only goal in this example is not a viable antecedent for the pronoun it. The noun phrases in train set-type examples, in contrast, can serve as antecedents for subsequent reference, even though they do not have narrow existence.

(30) Max wanted a train set for Christmas but when he opened his presents, [the train set $]_{i}$ wasn't there. His parents had forgotten to buy $\mathrm{it}_{i}$.

(31) We cancelled [the May meeting $]_{i}$. It $t_{i}$ was deemed unnecessary.

(32) Captain James Cook disproved the existence of [the Northwest Passage $]_{i}$ in 1778. $\mathrm{It}_{i}$ was not included on maps after that.

Another way of getting at the distinction is offered by Cooper (2013), who gives the following dialogue:
A: Sam is looking for the train set.
B: Which train set?
A: The one he was promised for Christmas.

Crucially, this dialogue is coherent even if there is no particular train set that Sam was promised, and the only promise made was that he would receive a train set. In contrast, the which question response does not work with the NPs that give rise to anti-uniqueness effects.

(34) A: Sue and Jane both scored goals, so Jane didn't score the only goal.

B: \#Which goal?

We take the felicity of this kind of dialogue to be diagnostic of broad existence, and therefore infer from the strangeness of (34) that the only goal does not come with a broad existence presupposition. Thus, what anti-uniqueness effects show is that definite descriptions do not presuppose existence even in a broad sense which is not restricted to existence in reality.

\footnotetext{
13 A reviewer points out that these have an anaphoric quality. This points to the possibility that they may be understood as parallel to cases first discussed by Karttunen (1976), and termed modal subordination by Roberts (1989), except that in the above decontextualized examples the prior non-veridical context in which the relevant discourse entities (a train set, wine, May meeting, or Arctic sea passage, respectively) is introduced is implicit.

14 Note that the claim here is not that an anaphoric reading for it is impossible, but rather that it is impossible with the indexation indicated, such that $i t_{i}$ corefers with the only goal.
} 


\subsubsection{Local accommodation?}

Is there anything that can be done to defend the notion that definite articles lexically carry an existence presupposition in light of these facts? The reader may be reminded of the many examples in the literature in which a definite under negation fails to refer, as in following quote from Strawson (1964): "Whoever the Exhibition was visited by yesterday, it was not visited by the King of France, since there is no such person." This sentence is clearly incompatible with the existence of a king of France. Doesn't this militate equally against the assumption that the encodes an existence presupposition? No; there is a standard response: local accommodation (Heim 1983; van der Sandt 1992; Beaver and Zeevat 2007; Elbourne 2012). A local accommodation story amounts to an analysis where the presupposition ends up in the scope of negation and targeted by it. If definites presupposed existence and uniqueness, then after local accommodation, "it was not visited by the King of France" would convey the same information as "It is not the case that there exists a unique king of France who visited it." Could this be what is going on with anti-uniqueness ? $^{15}$

It is, in general, difficult to differentiate between, on the one hand, accounts on which a given meaning component is lexically encoded but systematically eliminated in the compositional process, and, on the other hand, accounts on which it is not lexically encoded. Identifying the predictions of a putative local accommodation story furthermore depends on the details of its implementation, in particular what the relationship between predicative and argumental definites is assumed to be. As far as we know, there is no existing account of predicative and argumental definites building on local accommodation that deals with the data in question. To support our contention that predicative definite descriptions do not lexically presuppose existence, we will assume a process of local accommodation, and then compare the predictions of our account to an alternative in which predicative the has a 'Fregean' lexical entry, as given above in $(9 b)$ :

$$
\lambda x .\left\{\begin{array}{l}
P(x) \text { if }|P|=1 \\
\text { undefined otherwise }
\end{array}\right.
$$

We will follow Heim (1983) as regards the circumstances in which local accommodation rather than global accommodation is expected to occur. She comments (Heim 1983 , p. 120) with reference to (36):

I suggest that the global option is strongly preferred, but the local option is also available in certain circumstances that make it unavoidable. Consider a concrete example. [(36) is] uttered in a context which is compatible with France having no king. By the global option, we end up with a context that entails that France has a king; this is presumably how we tend to read [(36)] in isolation. Under the local option, the resulting context will only entail that either France has no king or he didn't come. We will read [(36)] this way if we are for some reason

\footnotetext{
15 Strawson's discussion of "it was not visited by the King of France" does not use the later term "accommodation", but talks of non-referring definite descriptions being "absorbed into the predicate" (Strawson 1964). Since Strawson clearly intends this absorption to occur under the scope of the negation, the effect would presumably be much the same as that of local accommodation.
} 
discouraged from assuming France to have a king, e.g., if the speaker continues [(36)] with "because France doesn't have a king." Note that by stipulating a ceteris paribus preference for global over local accommodation, we recapture the effect of [Gazdar]'s assumption that presupposition cancellation occurs only under the threat of inconsistency.

(36) The king of France didn't come. (Heim 1983, ex. (16))

There has been further work on constraints on accommodation. However, the further constraints introduced by van der Sandt (1992) and Geurts (1999) would not qualitatively affect the discussion below, and the line of work initiated by Thomason (1990) does not provide an immediate way to drive predictions. Our assumption, then, will be that presuppositions are accommodated globally by default, and locally only on pain of inconsistency, this being the sole constraint on accommodation Heim (1983) discussed. ${ }^{16}$

Having settled on the importance of inconsistency in determining when local accommodation occurs, let us consider whether it would be inconsistent to accommodate existence globally in a case like (15b), repeated here as (37), in order to determine whether local accommodation is predicted.

Scott is not the only author of Waverley.

The presupposition that the contributes under the alternative Fregean account we are considering is that there is exactly one 'only author' (of the relevant book, reference to which will be suppressed in the following discussion). The sentence entails that Scott does not have the property 'only author'. These two propositions are not inconsistent with each other; taken together, they mean that there is exactly one author, and Scott is not it. So the ordinary semantic content of the sentence does not force local accommodation. But notice that as a matter of fact, the sentence intuitively implies that Scott is an author. This is because adjectival only carries a presupposition that the predicate it modifies (author in this case) applies to its subject (Scott in this case), just as adverbial only carries a prejacent presupposition. (We discuss this further in Sect. 2.5.) If this presupposition projects globally as well, then the sentence imposes three mutually inconsistent requirements:

- Scott is an author (presupposition from only)

- There is exactly one 'only author' (presupposition from the)

- Scott does not have the property 'only author' (entailment)

These three cannot be maintained at the same time. If Scott is an author and does not have the property 'only author', then there must be several authors, hence no 'only author'. But this contradicts the presupposition that there is exactly one 'only author'. So local accommodation would correctly be predicted to be preferred over global accommodation of all presuppositions in this case. Good news for the local accommodation account.

\footnotetext{
${ }^{16}$ Heim herself noted (immediately below the above cited passage) that she had "[stopped] far short of a general and precise formulation of the laws governing accommodation." See Beaver and Zeevat (2007) for extended discussion of work on the topic.
} 
But what if we locally accommodate the presupposition that Scott is an author (the presupposition from only), but not the existence and uniqueness presuppositions from the definite article? This should also resolve the inconsistency. Then we should get the interpretation that there is exactly one author and Scott is not it. This results in truthconditions identical to those of an equative interpretation, i.e. the sort of reading in which we take be to subcategorize for an entity in object position, rather than combining with a property. This equative reading can be brought out by the continuation, they are the same, as in e.g. Hesperus is Phosphorus; they are the same (Wang and McCready 2005).

On our view, equative readings with definite descriptions result not from global accommodation of an existence presupposition, but from a differently typed copula construction, one in which two individuals are equated. The possibility of an equative reading thus complicates our attempt to cleanly distinguish the predictions of our account from the putative accommodation account we are considering. In order to do so, we should consider a construction containing a definite in a position unambiguously requiring a property-denoting phrase. In such a construction, the accommodationbased model will still generate an equative-like interpretation in which existence is presupposed, whereas our model will not. We therefore move from considering be to considering verbs like consider, which can select for predicative expressions. Consider the following example:

I don't consider Scott the only author of Waverley.

A speaker who asserts this sentence would typically be committed to the existence of multiple authors. The supporter of the Fregean account would want to say that the existence presupposition is locally accommodated in this case. This could be justified on the grounds that global accommodation of all presuppositions would be inconsistent: we cannot simultaneously maintain that there is exactly one author of Waverley (existence presupposition from the), Scott is an author of Waverley (presupposition from only), and that Scott does not have the property 'only author of Waverley' (entailment, assuming that an utterance of 'I don't consider $\mathrm{X}$ to be $\mathrm{P}$ ' entails that ' $\mathrm{X}$ is not $\mathrm{P}$ '). But notice that, as above, local accommodation of the presupposition from only could equally well resolve the global inconsistency. And yet there is no equative-like reading for (38). So the question that proponents of a Fregean account with local accommodation would have to answer is why it should be the existence presupposition (the implication that there is a satisfier of the predicate 'only author') that is locally accommodated and not the presupposition from only (that Scott is an author).

It is worth noting (as pointed out to us by an anonymous referee) that there are circumstances in which someone uttering (38) would not appear committed to the existence of multiple authors, as illustrated in the continuation of (38) in (39).

(39) I don't consider Scott the only author of Waverley. I consider Burns the only author of Waverley.

In (39), the followup sentence has the effect of making it inconsistent to globally accommodate that Scott is an author of Waverley, regardless of whether predicative definites are Fregean or lack an existential presupposition. Therefore, on the account of accommodation we are considering, the proposition that Scott is an author of Waverley 
must be locally accommodated, independently of which assumptions are made about the meaning of definites. But this in turn means that examples like (39) do not provide evidence as regards whether the definite has an existence presupposition, since the results will be similar either way: it is implied that the speaker takes there to be exactly one author of Waverley, whether because the definite description carries a presupposition that a unique such individual exists, or because the followup sentence implies that the the speaker is under the misconception that Burns is such an individual.

The use of consider in the examples here is designed to eliminate the equative-like reading. Another way of achieving this effect is using coordination with adjectives:

(40) a. He is neither handsome nor the only man you'll ever meet.

b. Mary is neither stupid nor the only person to have made this mistake.

In (40a), for example, we do not get a reading presupposing existence of exactly one man the addressee will meet, denying that ' $h e$ ' is that individual. But that reading would be predicted to be available under a local accommodation story for reasons analogous to those given in connection with (38).

Returning to consider-like verbs, we can make a similar point without negation and a first person subject. Consider the following naturally-occurring examples.

(41) a. Meanwhile, the Enterprise computer has fallen in love with Captain Kirk and considers him the only person in the universe.

b. The film treats him as the only truthful man in the whole of Hollywood.

c. One political wag characterized him as the only man in America who could get away with wearing a toga.

d. Jackson managed to concoct a version of events which painted him as the only innocent party in the whole affair.

e. Orion... came to view him as the only spy he could trust.

f. The media, when it didn't utterly forget him [former US vicepresident Lyndon Johnson], depicted him as the only Democrat in Washington who wasn't creating a vigorous new America.

g. They regard him as the only authorized expositor of his own religion, and believe...

None of these imply that there is exactly one individual satisfying the description following only (person in the universe, truthful man in the whole of Hollywood, man in America who could get away with wearing a toga, etc.). Let us use $P$ as a label for the description following only. In these cases, the presupposition of only does not conflict with the proposition that there is exactly one $P$. The presupposition of only is the predication of $P$ upon the object of the verb ('him'). For example, in (41c), the presupposition contributed by only is that 'he' is a man in America who could get away with wearing a toga. This presupposition is consistent with the possibility that there is exactly one such man, combined with the entailment that some political wag characterized 'him' as having this property. So in this case, there is no global inconsistency if all of the presuppositions project, so local accommodation will not be 
forced. And yet the primary reading, if not the only reading, is one where existence of exactly one $P$ is not implied.

We cannot claim that no local accommodation story with a Fregean interpretation of definites could ever account for such examples, only that no extant account of accommodation does. Nor do we claim that local accommodation never occurs: a local accommodation mechanism like that proposed by Heim is entirely compatible with our account. But by assuming that existence is not lexically encoded by the definite article, we can account for the fact that existence implications fail to emerge in cases where their emergence would not produce global inconsistency, or where the global inconsistency could equally well be resolved through local accommodation of a different presupposition. On the present story, the examples above are correctly predicted not to presuppose that there is exactly one individual in the relevant classauthors, men you'll meet, people who've made some mistake, people in the universe, honest men in Hollywood, people who can wear togas, innocent parties, trustable spies, Democrats creating a vigorous new America, or authorized expositors of a religion, respectively.

\subsection{Uniqueness without existence}

We have argued that existence is not part of the lexical meaning of the. We argue that uniqueness, on the other hand, is. First, observe that stressing the gives rise to a reading on which uniqueness is at issue.

(43) $\{$ THE/\#The $\}$ man who can best her in a battle of wits does not exist- there are two.

The fact that emphasis on the can cause uniqueness to be at issue suggests that uniqueness is part of its meaning.

Further evidence comes from the fact that predicative definites prefer contexts in which it is assumed that there is only one satisfier of the relevant predicate, if there are any. Consider a situation in which an iguana has been dissected, and, pointing to an unidentified part, an observer utters one of the following sentences.

(44) a. I don't know whether iguanas have hearts, but is that the heart?

b. \#I don't know whether iguanas have bones, but is that the bone?

(44a) is felicitous, under the normal assumption that iguanas have only one heart if they have any. Under the equally plausible assumption that iguanas have multiple bones if they have bones at all, (44b) is infelicitous.

Under negation too, the definite article conveys uniqueness without existence, as shown by the following.

(45) a. That's definitely not the heart. Iguanas don't have hearts.

b. \#That's definitely not the bone. Iguanas don't have bones. 
This uniqueness presupposition projects from the antecedent of a conditional as well, as evidenced by the following contrast. ${ }^{17}$

(46) a. If that's the heart, then this must be a blood vessel.

b. \#If that's the bone, then this must be a tendon.

Here again, uniqueness is conveyed without existence; (46a) does not commit the speaker to the existence of iguana hearts, but the contrast between (46a) and (46b) shows that uniqueness is required in these cases. Note, furthermore, that in the above examples the relevant instance of the definite determiner is in an embedded positionin a question in (44), under negation in (45), and in the antecedent of a conditional in (46). The examples then illustrate not only the fact that there are uniqueness implications associated with definites, but that these implications are projective inferences. This, in turn, provides strong evidence that uniqueness is presupposed by definite descriptions, rather than being part of the ordinary at-issue meaning. Finally, note that if the definite article were replaced by the indefinite article in the above examples, the contrasts would disappear, suggesting that the implication is tightly attached to the definite, rather than arising from predicative descriptions more generally. We conclude that the definite article contributes a uniqueness presupposition even when the description it is part of functions predicatively.

Before presenting our analysis, we ought to mention that there are certain definite descriptions that seem not to presuppose uniqueness, which go under the heading of weak definites. Barker (2004) discusses examples like (47a), and notes that the variant in (47b) with the "double genitive" is unacceptable.
a. The baby's fully developed hand wrapped itself around the finger of the surgeon.
b. *... around the finger of the surgeon's.

This particular example was accompanied by a picture of the surgeon with all ten of his fingers intact. A similar example is the following (recall that intersections have four corners):

(48) He is standing at the corner of the intersection.

Such examples (which have been studied by Löbner 1985; Kadmon 1987; McNally 1992, 1998; Poesio 1994; Rawlins 2005, 2006; Barker 2004, i.a.) are limited to definite noun phrases headed by relational nouns followed by of PPs in which the object is not accompanied by the possessive marker 's. Thus they constitute a limited but systematic set of counterexamples to the generalization that the $X$ is acceptable only in contexts with at most one $X$. According to Barker (2004), such cases do not call for a loosening of the uniqueness restriction on the definite article, and can be analyzed in terms of an alternative mode of composition. This strategy is compatible with our analysis.

Another limited, systematic class of 'weak definites' is exemplified by cases like Lola is reading the newspaper, and Take the elevator. This kind of usage is limited to certain lexical items and does not exemplify the general case; Lola is reading

\footnotetext{
17 Note that (46b) may become felicitous if bone is understood as a mass term, though such a reading is perhaps less accessible for (45b), presumably because there the pluralized form of the count-noun (bones) also occurs.
} 
the newspaper behaves quite differently from Lola is reading the book, as Carlson et al. (2006) show in a set of eye-tracking experiments. Aguilar-Guevara and Zwarts (2010) give an analysis accommodating this kind of weak definite without abandoning the assumption that the definite article contributes a uniqueness presupposition by invoking kind reference, and Schwarz (2012) offers a slightly different proposal in terms of kinds, also maintaining uniqueness for definites. This work encourages us to believe that a unified analysis of definite descriptions involving uniqueness is possible, although we will not attempt to apply our theory to these cases here.

\subsection{Proposed lexical entry for the}

We hope to have convinced the reader by now that it is desirable to have an $\langle e, t\rangle$ analysis of predicative definites on which existence is not presupposed but uniqueness is. Our proposal is just that: the "Weak Fregean" alternative mentioned above, repeated here.

$$
\lambda x .\left\{\begin{array}{l}
P(x) \text { if }|P| \leq 1 \\
\text { undefined otherwise }
\end{array}\right.
$$

We formalize the presupposition using Beaver's (1992) $\partial$-operator (pronounced 'partial operator'), using the semantics of Beaver and Krahmer (2001), so our lexical entry for the is as follows ${ }^{18}$ :

$$
\begin{aligned}
& \text { Lexical entry: the } \\
& \text { the } \rightsquigarrow \lambda P . \lambda x \cdot[\partial(|P| \leq 1) \wedge P(x)]
\end{aligned}
$$

The $\partial$-operator gives us a clean and easy notation with which to show how the presuppositions of complex expressions relate to the presuppositions of the parts, and the logic that accompanies it enables a reasonable treatment of presupposition projection within static semantics. Beaver and Krahmer (2001) argue, extending a point made by Peters (1979), that this kind of system has sufficient expressive power to be comparable to a dynamic treatment in coverage.

A formula $\partial(\phi)$ is true (and thus, at least in conjunctions, can be ignored) when $\phi$ is true, but lacks a classical truth-value when $\phi$ is not true. Thus the presupposition in (50) implies that ' $x$ is the $P$ ' has a (classically) defined truth value when the number of $P \mathrm{~s}$ is no greater than one. This leaves open the possibility that there are none; hence the absence of an existence implication. For example, putting this lexical entry for the together with a common noun like moon gives us the following:

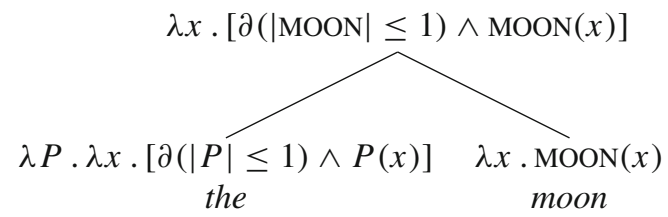

\footnotetext{
18 See the appendix for the details of the logic and an implementation that takes intensionality into account. We use the following abbreviations: (i) $|P|=1$ is short for $\exists x[P(x) \wedge \forall y[P(y) \rightarrow x=y]]$; (ii) $|P| \leq 1$ is short for $\forall x[P(x) \rightarrow \forall y[P(y) \rightarrow x=y]]$; (iii) $P \subseteq Q$ is short for $\forall x[P(x) \rightarrow Q(x)]$.
} 
Table 1 Alternative lexical meanings for singular the

\begin{tabular}{lll}
\hline Label & Definition & Author(s) \\
\hline $\operatorname{THE}_{\langle e t, e t\rangle}^{W F}$ & $\lambda P \cdot \lambda x \cdot[\partial(|P| \leq 1) \wedge P(x)]$ & Coppock and Beaver (2012b, here) \\
$\operatorname{THE}_{\langle e t, e t\rangle}^{R}$ & $\lambda P \cdot \lambda x \cdot[|P|=1 \wedge P(x)]$ & Winter (2001), Fara (2001) \\
$\operatorname{THE}_{\langle e t, e t\rangle}^{F}$ & $\lambda P \cdot \lambda x \cdot[\partial(|P|=1) \wedge P(x)]$ & Winter (2001) \\
$\operatorname{THE}_{\langle e t,\langle e t, t\rangle\rangle}^{R}$ & $\lambda P \cdot \lambda Q \cdot[|P|=1 \wedge P \subseteq Q]$ & e.g. Partee (1986) \\
$\operatorname{THE}_{\langle e t,\langle e t, t\rangle\rangle}^{F}$ & $\lambda P \cdot \lambda Q \cdot[\partial(|P|=1) \wedge P \subseteq Q]$ & e.g. Barwise and Cooper (1981) \\
$\operatorname{THE}_{\langle e t, e\rangle}^{F}$ & $\lambda P \cdot \iota x P(x)$ & Partee (1986), Elbourne (2012) \\
$\operatorname{THE}_{\langle e, e\rangle}$ & $\lambda x \cdot x$ & Löbner (1985, 2011) \\
\hline
\end{tabular}

So the moon denotes the property of being a moon, defined if there is no more than one. $^{19}$

Let us consider how this proposal compares to other approaches, summarized in Table 1. There are two general strategies for getting an $\langle e, t\rangle$-type denotation for definite descriptions. One could take the predicative case as basic, as we have done, or take the argumental case as basic, starting out with a denotation that produces something of another type, and then shift it into a function of type $\langle e, t\rangle$. Besides our own, we are aware of two analyses in the former category (taking the predicative use as basic): those described above as "Russellian" and "Fregean" versions of the predicative analysis, repeated here using the $\partial$ operator:

$$
\begin{array}{ll}
\text { a. } & \lambda P \cdot \lambda x \cdot[|P|=1 \wedge P(x)] \\
\text { b. } & \lambda P \cdot \lambda x \cdot[\partial(|P|=1) \wedge P(x)]
\end{array}
$$

$$
\begin{array}{r}
\operatorname{THE}_{\langle e t, e t\rangle}^{R} \\
\operatorname{THE}_{\langle e t, e t\rangle}^{F}
\end{array}
$$

We gloss these as $\operatorname{THE}_{\langle e t, e t\rangle}^{R}$ and $\operatorname{THE}_{\langle e t, e t\rangle}^{F}$ for the obvious reasons. Neither fulfills the criteria we have laid out in the foregoing sections; the Russellian version treats uniqueness as an ordinary entailment rather than a presupposition, among other problems, and the Fregean version presupposes existence.

What about taking the argumental use of definite descriptions as basic, and letting the predicative use be derived from that using a shifting operation, as Partee (1986) does? One immediate hurdle one would face in taking this strategy is choosing which argumental use to start with. As we argue in the next section, definite descriptions have both determinate and indeterminate uses, where the former carries an existence presupposition and the latter has existence as an at-issue entailment. But in either case, the existence component would survive in the transition to the predicative variant. Let us see why this is so.

Suppose we start out with a quantificational meaning, type $\langle e t,\langle e t, t\rangle\rangle$. Partee (1986) defines the Russellian variant in (53a) and Barwise and Cooper (1981) define the Fregean variant in (53b) (though not in these terms).

\footnotetext{
${ }^{19}$ Here, and throughout, we are ignoring the fact that uniqueness must be relativized to salience. We believe that there are a number of ways of taking salience into account which are consistent with our approach. We return briefly to this issue in Sect. 5 .
} 


$$
\begin{array}{llc}
\text { a. } & \lambda P \cdot \lambda Q \cdot[|P|=1 \wedge P \subseteq Q] & \operatorname{THE}_{\langle e t,\langle e t, t\rangle\rangle}^{R} \\
\text { b. } & \lambda P \cdot \lambda Q \cdot[\partial(|P|=1) \wedge P \subseteq Q] & \operatorname{THE}_{\langle e t,\langle e t, t\rangle\rangle}^{F}
\end{array}
$$

To get an $\langle e, t\rangle$-type denotation from these, we can apply Partee's BE shift, which takes a generalized quantifier $G$ to $\lambda x . G(\lambda y \cdot y=x)$. If we combine this with $\operatorname{THE}_{\langle e t,\langle e t, t\rangle\rangle}^{R}$, then neither existence nor uniqueness ends up as being presupposed. If we combine it with $\operatorname{THE}_{\langle e t,\langle e t, t\rangle\rangle}^{F}$, then both do. Yet what we have argued is that uniqueness is presupposed, and existence is not.

A further problem with the Partee analysis is that it stipulates a lexical ambiguity; the is treated as ambiguous between $\operatorname{THE}_{\langle e t,\langle e t, t\rangle\rangle}^{R}$ and $\operatorname{THE}_{\langle e t, e\rangle}^{F}$. The former is used along with the $\mathrm{BE}$ type-shift to generate the denotation for the on which existence is not presupposed, and the latter yields the presuppositional interpretation. Ideally, we would not have to stipulate this ambiguity. Moreover, as discussed by Winter (2001, ex. (24)), the BE type-shift overgenerates, giving coherent readings to sentences such as:

(54) \#John and Mary are exactly zero friends of mine.

The BE shift would allow this sentence to receive an interpretation along the lines of 'John and Mary have the property of not being friends of mine'.

Alternatively, we might consider starting out with a truly Fregean analysis of definite descriptions, on which they are "complex proper names," i.e., type $e$. This is the analysis put forth in Heim and Kratzer's (1998) textbook. The analysis advocated by Elbourne (2012) falls into this category, with the added twist that definite descriptions come with a situation variable in the syntax. A variant on this idea comes from Löbner (1985, 2011), who argues that common nouns like moon have denotations of type $e$, and hence that the phrase that definite descriptions combine with is already of type $e$.
a. $\quad \lambda P . \iota x P(x)$
b. $\quad \lambda x \cdot x$
$\mathrm{THE}_{\langle e t, e\rangle}^{F}$
$\mathrm{THE}_{\langle e, e\rangle}$

To get a predicative denotation from these, we can apply Partee's IDENT operator, which takes $j$ of type $e$ to the property $\lambda x . x=j .{ }^{20}$ But regardless of which of the above variants is adopted, the result is that predicative definites are predicted to presuppose both existence and uniqueness.

Putting the relevant analyses of the together with the applicable type-shifting operations, we get the possible $\langle e, t\rangle$ analyses of the moon in Table 2 . The column labelled ' $\partial(\leq 1)$ ?' indicates for each analysis whether uniqueness is presupposed, and the one labelled ' $\partial(\geq 1)$ ?' indicates whether existence is presupposed. Only the Weak Fregean analysis satisfies both of the criteria we are after: a uniqueness presupposition, but no existence presupposition. This illustrates an advantage of the overall strategy on which the predicative case is taken as basic and existence is introduced when needed. If one were to start off with the argumental cases and derive the predicative ones from them, a mechanism would be needed for removing the existence presupposition (or entailment, as the case may be). Taking predicative uses as basic obviates the need for a destructive step of this kind.

\footnotetext{
20 Löbner (p.c., 2012) has indicated that this is the strategy that he would be inclined to take with respect to predicative definites.
} 
Table 2 Predicative analyses of the moon showing uniqueness and existence presuppositions

\begin{tabular}{|c|c|c|c|}
\hline Analysis & Author & $\partial(\leq 1) ?$ & $\partial(\geq 1) ?$ \\
\hline $\mathrm{THE}_{\langle e t, e t\rangle}^{W F}(\mathrm{MOON})$ & Coppock and Beaver & Yes & No \\
\hline $\mathrm{THE}_{\langle e t, e t\rangle}^{R}(\mathrm{MOON})$ & Winter, Fara & No & No \\
\hline $\mathrm{THE}_{\langle e t, e t\rangle}^{F}(\mathrm{MOON})$ & Winter & Yes & Yes \\
\hline $\mathrm{BE}\left(\mathrm{THE}_{\langle e t,\langle e t, t\rangle\rangle}^{R}(\mathrm{MOON})\right)$ & Partee & No & No \\
\hline $\mathrm{BE}\left(\mathrm{THE}_{\langle e t,\langle e t, t\rangle\rangle}^{F}(\mathrm{MOON})\right)$ & - & Yes & Yes \\
\hline $\operatorname{IDENT}\left(\mathrm{THE}_{\langle e t, e\rangle}^{F}(\mathrm{MOON})\right)$ & Partee & Yes & Yes \\
\hline $\operatorname{IDENT}\left(\mathrm{THE}_{\langle e, e\rangle}\left(\mathrm{M}_{e}\right)\right)$ & Löbner & Yes & Yes \\
\hline
\end{tabular}

\subsection{Analysis of the only}

With the lexical entry for the in (50), we can explain why a sentence like (15b), repeated in (56), gives rise to the inference that there are multiple authors of Waverley.

(56) Scott is not the only author of Waverley.

We use the following lexical entry for only ${ }^{21}$ :

\section{Lexical entry: only}

$$
\text { only } \rightsquigarrow \lambda P . \lambda x \cdot[\partial(P(x)) \wedge \forall y[x \neq y \rightarrow \neg P(y)]]
$$

Representing the extension of 'author of Waverley' as AUTHOR(W), we have that the extension of 'only author of Waverley' is:

$$
\lambda x .[\partial(\operatorname{AUThOR}(\mathrm{W})(x)) \wedge \forall y[x \neq y \rightarrow \neg \operatorname{AUTHOR}(\mathrm{W})(y)]]
$$

The non-presupposed content says that nothing other than $x$ is an author.

On this analysis, adjectival only, like adverbial only, has a positive component and a negative component. The negative component is the universal, or 'exclusive' part of the meaning, and this is typically at issue. The positive component, which is presupposed, is typically what is referred to as the 'prejacent', viz. the proposition that would be expressed by the clause containing adverbial only, if the only were not there. For adjectival only, we analyze the presupposition analogously, as a proposition derived from the nominal that only modifies. ${ }^{22}$ Evidence for the presuppositional status of

$\overline{21}$ Coppock and Beaver (2012a) incorporate plurality into the system and define only as follows:

$$
\text { only } \rightsquigarrow \lambda P . \lambda x .[\partial(P(x)) \wedge \forall y[x \prec y \rightarrow \neg * P(y)]]
$$

where $\prec$ denotes the proper sub-individual (sometimes called part-of) relation, and $*$ is a cumulativity operator, so $* P$ denotes the closure of $P$ over the individual sum operation. This accounts for anti-uniqueness effects with plurals, as in Scott and Ballantyne are not the only authors of 'Waverley'. We restrict our attention to the singular case in the present article.

22 In general, Coppock and Beaver $(2011,2014)$ argue that exclusives all presuppose that there is some true answer to the current question under discussion (CQ) that is at least as strong as $p$, and assert that there is no true answer that is stronger than $p$, where $p$ is the prejacent. Exclusives differ with respect to 
this meaning component comes from sentences we have already seen: a negated only predication as in (56) implies that the subject bears the nominal property.

Putting this together with our proposed lexical entry for the, we have the following denotation for the only author (using ONLY as an abbreviation for the translation of only, and abbreviating the translation for the as THE) ${ }^{23}$ :

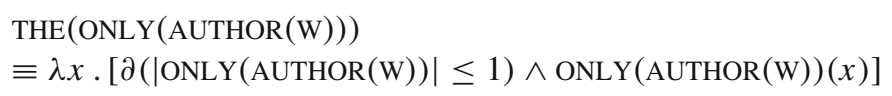

Note that we intend the $\equiv$ symbol as an expression of the meta-language signifying that the object-language expressions it joins are semantically equivalent. (Here the 'object language' is the logical representation language IL3, defined in the appendix.)

The presupposition of the definite article (the first conjunct in the second line in (59)) will be satisfied if there is no more than one 'only author'. This is true by definition. Thus ONLY(AUTHOR(W)) always satisfies the presuppositional requirements of the definite article, and the presupposition of the definite article does not add to the meaning. We therefore have the following equivalence for all $\pi$ :

$$
\operatorname{THE}(\operatorname{ONLY}(\pi)) \equiv \operatorname{ONLY}(\pi)
$$

In words, the only $P$ means the same thing as only $P$. In general, when the uniqueness presupposition is trivially satisfied, the has no impact on the denotation.

Now let us consider the example with negation, (56). We can assume that not is a predicate-modifier that introduces negation, and that the copula is an identity function on predicates:

\section{(61) Lexical entry: not}

not $\rightsquigarrow \lambda P . \lambda x . \neg P(x)$

(62) Lexical entry: is

is $\rightsquigarrow \lambda P . P$

And we represent Scott with the individual constant $\mathrm{S}$. The derivation for the whole sentence is in (63). Note that all of the right-hand daughter nodes have type $\langle e, t\rangle$.

\footnotetext{
Footnote 22 continued

semantic type (adjectival exclusives like only and mere being of type $\langle$ et, et $\rangle$ ) and constraints imposed on the CQ. Adjectival only requires the question to be 'What things are $P$ ?', where $P$ is the property denoted by the modified nominal, so the way that it instantiates the general schema for exclusives is equivalent to the lexical entry in (57).

23 The representation in (59) can be expanded as follows:

$\lambda x . \partial(|\lambda z . \partial(\operatorname{AUTHOR}(\mathrm{W})(z)) \wedge \forall y[z \neq y \rightarrow \neg \operatorname{AUTHOR}(\mathrm{W})(y)]| \leq 1) \wedge \partial(\operatorname{AUTHOR}(\mathrm{W})(x)) \wedge \forall y[x \neq$ $y \rightarrow \neg \operatorname{AUTHOR}(\mathrm{W})(y)]$.
} 
(63)

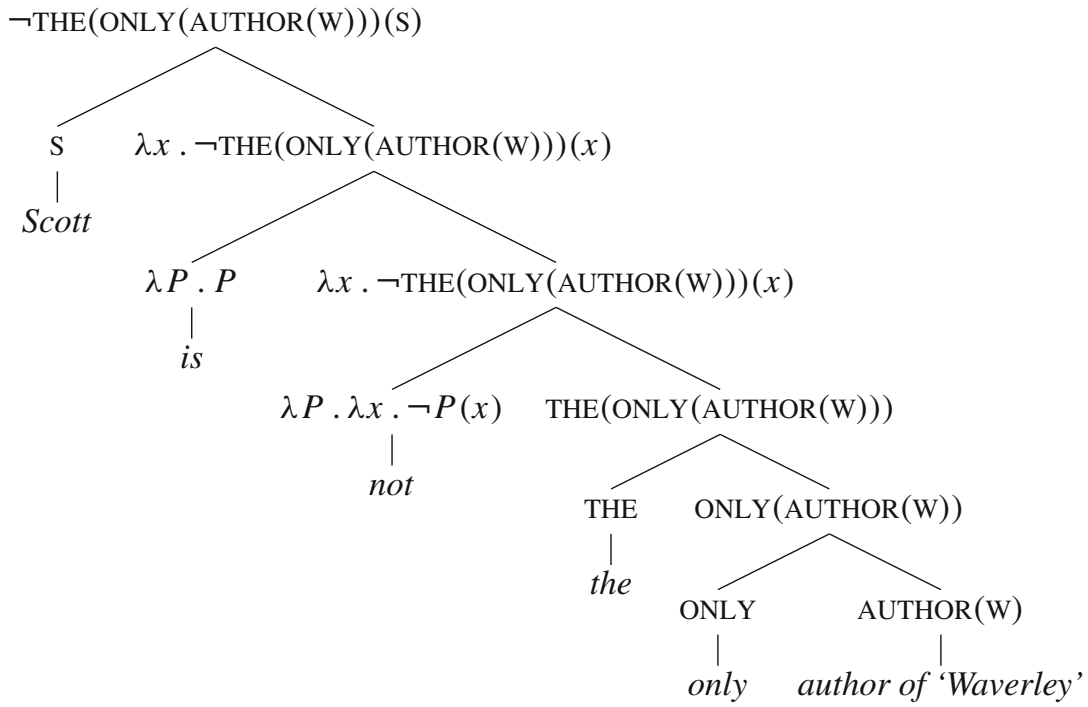

The sentence is then predicted to have two presuppositions:

- $|\operatorname{ONLY}(\operatorname{AUTHOR}(\mathrm{W}))| \leq 1$ (from the)

- AUTHOR(W)(S) (from only).

The first is trivial, as there is never more than one sole author of a given book. So (56) just presupposes that Scott is an author of Waverley, and denies that there are no others:

$$
\partial(\operatorname{AUTHOR}(\mathrm{W})(\mathrm{S})) \wedge \neg \forall y[\mathrm{~S} \neq y \rightarrow \neg \operatorname{AUTHOR}(\mathrm{W})(y)]
$$

The sentence thus implies that there are multiple authors of the book, even though there is no only author of the book. So there is no inherent conflict in the meaning, and we get the anti-uniqueness inference, namely, that Scott is an author of Waverley and so is somebody else.

\subsection{Predicative $a$, and how the can block it}

Let us now observe a consequence of this proposal. We have argued that predicative definite descriptions are type $\langle e, t\rangle$, and signal a uniqueness presupposition but no existence presupposition. The kind of uniqueness involved, which we have labelled 'weak uniqueness', is independent of existence.

If we took away the uniqueness presupposition as well, what we would have left is what some have proposed for predicative indefinites. Winter (2001, p. 146), for example, proposes that the indefinite article is a vacuous identity function on predicates. ${ }^{24}$ We follow this line as well.

24 Heim and Kratzer (1998, p. 62) also give this entry, and ideas to this effect are expressed by Fara (2001). A more distant precedent comes from Partee (1986), who allows the indefinite article to acquire this meaning through the type-shifting operation BE, applied to the basic meaning of $a(n)$ as an existential quantifier. Partee's analysis is a variation on Montague's approach to predication, as discussed by Winter (2001, p. 139ff.). 
(65) Lexical entry: $a(n)$

$a(n) \rightsquigarrow \lambda P . P$

Under this assumption, the definite and the indefinite articles are both identity functions on predicates, but the definite article has a smaller domain, restricted to those predicates satisfying weak uniqueness. ${ }^{25}$

If definites and indefinites are presuppositional variants, then the principle Maximize Presupposition should yield a ceteris paribus preference for the presuppositionally stronger variant, which is the definite article in this case. (See below for a technical implementation.) Given what we have said so far about only, this predicts that, absent material which intervenes between the determiner and the exclusive semantically, only cannot occur with indefinite determiners. This prediction is borne out.

(66) Scott is $\{$ the/*an $\}$ only author of Waverley.

This fact supports the view that definite and indefinite determiners have the same semantic type and at-issue content. It also provides indirect evidence for the presence of a uniqueness presupposition with predicative definites despite the absence of an existence presupposition; if there were no uniqueness presupposition then there would be no difference in meaning between the and $a$ and this fact could not receive the same kind of explanation.

The picture is not quite so simple, however, because the prohibition against indefinite articles with only is not absolute. The most idiomatic counterexample is an only child, and there are variants on this: an only son, an only grandchild. We will offer a tentative analysis of such cases below, but it is as well to note first that these are not counterexamples to our blocking analysis per se. The reason is that in all such cases it is manifest that weak uniqueness need not be satisfied. For example, it is perfectly reasonable to utter (67), in which it is manifest that only child applies to multiple entities:

(67) In China it is common for every student in a class to be an only child.

The issue is not then that sometimes indefinites are used even though weak uniqueness is satisfied, but rather that sometimes exclusive DPs lack weak uniqueness in the first place. Thus these examples do not directly challenge our analysis of definiteness marking and blocking; the problem they pose has more to do with the analysis of how only combines semantically with the head noun in such cases.

Another case in which indefinite articles can combine with only is when a further indefinite noun phrase is contained inside the nominal. Consider the following naturally occurring example (which matches an archetype pointed out to us by Roger Levy):

(68) Over the past 29 years, I've tried to contact everyone I can around the world who's been an only survivor of a large plane crash.

\footnotetext{
25 We will ignore dynamic aspects of meaning, in particular the introduction and picking up of discourse referents, throughout this paper; we hope to develop a dynamic version of the theory in future work.
} 
The nominal an only survivor of a large plane crash is clearly interpreted to mean: a person such that there is a large plane crash of which that person is the only survivor. This paraphrase makes it clear that a large plane crash must take semantically wider scope than only ${ }^{26}$ :

$$
\begin{aligned}
& \text { only survivor of a plane crash } \\
& \rightsquigarrow \lambda x . \exists z[\operatorname{PLANE}-\mathrm{CRASH}(z) \wedge \operatorname{ONLY}(\lambda y \cdot \operatorname{SURVIVED}(z)(y))(x)]
\end{aligned}
$$

Crucially, although the NP in question contains the word only, the meaning in (69) can hold of more than one individual: it will hold of as many individuals as there are large plane crashes with a single survivor. Therefore, in this case the presuppositions of the are not met, so no blocking is expected to occur.

Now, notice that the only survivor of a large plane crash appears to be a reasonable substitute for an only survivor of a large plane crash in (68). The definite would be licensed if a large plane crash scoped higher, completely outside of the DP, say to the level of the VP, or even outside of the relative clause. This would yield essentially the same truth conditions. So Maximize Presupposition must be defined in a way that is sensitive to the details of the derivation, rather than looking at sentence meanings as a whole. The implementation we offer later in this section has this property.

Let us now return to the case of an only child. We suggest that a crucial feature of such cases is that child can be understood relationally, with the family or parents implicitly occupying a possessor role that could have been made explicit with an of PP. Thus we speculate that an only child is understood not in terms of the ordinary meaning of child, but rather as having a meaning similar to what would be derived compositionally from an only child of some parents. If so, then we can follow the analysis of (68): the licensing of the indefinite will be predicted provided the implicitly existentially quantified parents (or, perhaps, family situation) can be given higher scope than only. This has the effect that only child does not satisfy weak uniqueness, since there will be as many only children as there are families that have exactly one child. Again, the indefinite is predicted to be licensed. However, we posit that the operation that allows the implicitly quantified parents to take scope over an adjacent modifier is not freely available, but rather is derived by analogy with what would happen in the structure with explicit parents or family, and that such use of analogy is only available in restricted idiomatic uses rather than being freely available.

So an only is usually blocked because the property denoted by a phrase only $N$ usually obeys weak uniqueness, and in all such cases Maximize Presupposition causes the speaker to prefer the to an. However, we predict a systematic class of exceptions,

26 This meaning can be obtained with the following type-shift:

$$
T \mapsto \lambda Q \cdot \lambda M \cdot \lambda x \cdot Q(\lambda z \cdot M(\lambda y \cdot T(z)(y))(x))
$$

In our case: $T$ corresponds to survivor (type $\langle e, e t\rangle$ ), $Q$ corresponds to (of) a plane crash (type $\langle e t, t\rangle$ ), and $M$ corresponds to only (type $\langle e t, e t\rangle$ ). Applied to survivor, this produces:

$$
\text { survivor } \rightsquigarrow \lambda Q \cdot \lambda M \cdot \lambda x \cdot Q(\lambda z \cdot M(\lambda y \cdot \operatorname{SURVIVED}(z)(y)))
$$

After combining with of a plane crash and then only, we obtain (69). 
cases where an only surfaces, occurring whenever weak uniqueness is not satisfied. ${ }^{27}$ And weak uniqueness is clearly, but perhaps sadly, not satisfied for the many people who have no siblings, or who survived crashes which killed the remaining passengers and crew. We have seen that such examples may be analyzed in terms of a further existential within the nominal, which intervenes semantically between the determiner and the exclusive, and which may be implicit.

Let us now consider how to define the Maximize Presupposition principle in a way that captures these facts. Some formulations of Maximize Presupposition (e.g. Heim 1991; Schlenker 2012) are not adequate for the intended application because they are defined in terms of sentence-meanings rather than expression meanings. ${ }^{28}$ Since the definite article does not contribute any meaning to an inherently unique description, the meaning of the sentence with the definite article is the same as the meaning of the sentence with the indefinite article. So the rule must compare expressions rather than sentences, as suggested by Percus (2006). Furthermore, as mentioned above, the definition must also compare alternative derivations rather closely, so that an only survivor of a plane crash is not blocked by the only survivor of a plane crash.

We begin by defining the relative presupposition strength of expressions which have the same ordinary entailments. Since entailment is standardly defined for propositiondenoting expressions, and we wish to apply the principle to expressions of other types, our first step must be to define an appropriate cross-categorial notion of equivalence with respect to classical entailment. In order that we can analyze presuppositions in a fully compositional grammar fragment, the logic defined in the appendix includes undefined entities of every type. We say, following Haug (2013), that an entity is defined if it is not an undefined object and is not a function whose range includes an undefined object. We can then explicate classical equivalence as follows:

\section{(70) Classical equivalence}

Expressions $\alpha$ and $\beta$ are classically equivalent if and only if for any sequence of defined entities $d_{1}, \ldots, d_{n}$, model $M$, assignment $g$, and world $w$ such that $\llbracket \alpha \rrbracket^{M, g, w}\left(d_{1}\right) \ldots\left(d_{n}\right)$ and $\llbracket \beta \rrbracket^{M, g, w}\left(d_{1}\right) \ldots\left(d_{n}\right)$ both yield classical truth values, the values are the same.

\footnotetext{
27 A reviewer points to a class of web examples of an only where weak uniqueness might be argued to be satisfied, including:

(i) In this book, the author will share with you an only system that is based on his 7 years of researching, helping you cure your heartburn for good.

(ii) But sorry, I personally would not suggest that, it's just not a good investment as an only system... unless you know your need REALLY well and ...

These are not grammatical according to our own intuitions, but their existence could be explained under the assumption that the producers of these sentences have a lexical entry for only on which it is a synonym of what Coppock and Beaver (2014, p. 43) call 'relational sole', which is a function from relational nouns to relational nouns. Coppock and Beaver (2014) suggest that the relational argument can be existentially bound based on cases like Many sole proprietors require professional advice for this phase of their income tax report. The same process would allow for the combination of sole proprietor with an indefinite determiner, and may be at work in cases like (i) and (ii) above. Whether or not such a meaning for only is available appears to be a matter of dialectal variation.

28 Our thanks to Luka Crnic for pointing this out to us.
} 
It follows from this definition that the (translation of the) definite article is classically equivalent to the (translation of the) indefinite article. We introduce a similarly category-independent way of comparing presuppositions:

\section{(71) Relative Presuppositional Strength}

The presuppositions of $\alpha$ are at least as strong as those of $\beta$ if and only if for any sequence of defined entities $d_{1}, \ldots, d_{n}$ such that $\llbracket \beta \rrbracket^{M, g, w}\left(d_{1}\right) \ldots\left(d_{n}\right)$ has a classical truth value, $\llbracket \alpha \rrbracket^{M, g, w}\left(d_{1}\right) \ldots\left(d_{n}\right)$ also has a classical truth value.

\section{(72) Presuppositional Domination}

Expression $\alpha$ presupositionally dominates expression $\beta$ just in case $\alpha$ and $\beta$ are classically equivalent, and $\alpha$ has presuppositions at least as strong as $\beta$ but not vice versa.

Since the indefinite article denotes an identity function on properties, $\mathrm{AN} \equiv \lambda P . P$, it is clear that whenever we pick fully-defined objects $J$ of type $\langle e, t\rangle$ and $k$ of type $e$, $\llbracket \operatorname{AN} \rrbracket(J)(k)$ will have a classical value (in any model). But $\llbracket \mathrm{THE} \rrbracket(J)(k)$ does not always have a classical truth value. So (the translation of) the presuppositionally dominates (the translation of) $a(n)$.

In modeling how speakers choose between definites and indefinites, we must take account of the fact that the choice is dependent on context, as shown in the examples in (73):

a. I don't know how many books Frida has written. But as it happens, I'm now reading (a/\#the) book she wrote.

b. Frida has written exactly one book. But as it happens, I'm now reading $(\# \mathrm{a} /$ the $)$ book she wrote.

To model the fact that the the presupposition of the definite is satisfied in (73b), but not in (73a), we will follow Stalnaker (1978), and define notion of a context as a set of worlds which is successively refined as new utterances are accepted:

\section{(74) Update}

The update of a context $C$ (a set of worlds) with a sentential meaning $p$ is defined iff $p$ is defined at every world in $C$. In that case the updated context is just the subset of worlds in $C$ where $p$ is true.

Let us say that replacing an occurrence of a lexical item $\alpha$ by $\beta$ in a derivation yields a new derivation with $\beta$ substituted for $\alpha$ but in which all other lexical entries are identical, and all composition rules and all sequences of type-shifting rules are applied identically. We can now define the Maximize Presupposition principle as follows:

\section{Maximize Presupposition}

In a context $C$, lexical item $\alpha$ blocks $\beta$ in a derivation iff (i) $\alpha$ and $\beta$ are competitors, (ii) $\alpha$ presuppositionally dominates $\beta$, and (iii) replacing $\alpha$ by $\beta$ does not affect how $C$ would be updated. 
It should now be clear why $a$ is infelicitous in the second sentence in (73b). After updating with the first sentence, the context will only contain worlds in which there is exactly one book written by Frida. In this context, updates with both the definite and indefinite versions of the second sentence are defined, and would produce an identical revision to the context (i.e. the removal of all worlds where the speaker is not reading Frida's book). However, the definite dominates the indefinite, resulting in blocking, and hence the infelicity of the indefinite.

Similarly, Maximize Presupposition correctly rules out *Scott is an only author of 'Waverley'. In order to show that Maximize Presupposition as formulated here renders a sentence ungrammatical, one must consider all derivation pairs, but in this case there are not so many, as there are no quantifiers and no type-shifting operations. Since the presuppositionally dominates $a$ and the propositions that the sentences containing them give rise to are classical, the update to the context set will always be defined, so the sentence with the will always block the sentence with $a .^{29}$

What this formulation does not rule out is for example Scott is an only survivor of a plane crash, even though Scott is the only survivor of a plane crash is also available with the same meaning. The latter acquires the same meaning through a different derivation, not the one that gives a plane crash scope above only within the description. The presuppositions that the would give rise to under that derivation would not be satisfied in any context in which multiple crashes have each yielded a singleton survivor.

\section{Putting existence and uniqueness back together}

\subsection{Challenge: unifying definites and indefinites}

Now that we have separated existence and uniqueness, we need to put them back together again. The proposals we have made for predicative the and $a$ will not suffice for argumental descriptions, because, on a standard view, a description in an argument position should denote something that can combine with a property to produce a truth value, either an individual (type $e$ ) or a generalized quantifier (type $\langle e t, t\rangle$ ). Furthermore, both definites and indefinites give rise to existence implications in argument position. The question we explore in this section is whether there is a common set of principles giving rise to existence implications for both definites and indefinites. The answer, we suggest, is yes. This is the heart of our proposal.

Our analysis matches that of Fara (2001) in two respects: first, she analyzes definite descriptions as predicates, and, second, she aims for a uniform analysis of

\footnotetext{
29 In this paper we make no attempt to analyze the mass/count distinction. However, it is worth noting that the indefinite article in English is more restricted than the definite article, in that it is limited to count nouns (hence the/a thing but the/*a stuff). In extending our account to incorporate the mass/count distinction in our system, it would be crucial to implement the restriction of indefinites to count nouns syntactically, rather than as a semantic presupposition, since if it were a semantic presupposition then the would no longer presuppositionally dominate $a$. Thus we propose that the indefinite restriction be implemented syntactically, as an agreement or feature checking relationship between the indefinite and its complement. Support for such an analysis comes from the arbitrariness of the mass/count distinction, e.g. the fact that furniture has mass syntax, despite the fact that the current authors own only quantized furniture.
} 
existence implications for both definites and indefinites. However, we do not adopt her assumption that definite descriptions in argument position always acquire existence through existential closure. On a straightforward interpretation of her proposal, doing so leads to a Russellian analysis for argumental definites, in which existence is uniformly an entailment rather than a presupposition. As Elbourne (2012) points out, Fara's (2001) analysis is for that reason subject to the general problem with Russellian analyses illustrated in (76): These two sentences are incorrectly predicted to entail each other.

(76) a. It's possible that the ghost in Hans's attic is being noisy.

b. It's possible that there is exactly one ghost in Hans's attic and it is being noisy.

Intuitively, they are not equivalent; (76a) commits the speaker to the existence of a ghost while (76b) does not.

In general, the challenge for those who would like to find a unified set of principles associating definite and indefinite descriptions with their existence implications is the fact that definites and indefinites differ as to the discourse status of the existence inference. Argumental definites typically presuppose both existence and uniqueness, so both (77a) and its negated variant (77b) imply that there was a single invited talk.

a. Chris saw the (only) invited talk.

$\models$ There was exactly one invited talk.

b. Chris didn't see the (only) invited talk.

$\models$ There was exactly one invited talk.

These examples may be contrasted with the following predicative variants; while (78a) implies that there was a single invited talk (indeed, affirms it), that inference does not follow from the negated variant (78b).

(78) a. That was the only invited talk.

$\models$ There was exactly one invited talk.

b. That wasn't the only invited talk.

$\forall$ There was exactly one invited talk.

Thus, while predicative definites do not presuppose existence, those that are arguments of verbs like see typically do.

Indefinite noun phrases also give rise to existence implications in argument positions, but for standard uses of indefinites, there is arguably no grammatically triggered presuppositional requirement of existence. The existence implication in (79a), for example, does not survive embedding under negation as in (79b).

(79) a. Chris saw an invited talk.

$\models$ There was at least one invited talk.

b. Chris didn't see an invited talk.

(No entailment that there were any invited talks.)

So far the contrast between existence presuppositions of definites and indefinites seems straightforward, but there is a twist. Not all argumental definites have existence presuppositions. This is shown by the fact that anti-uniqueness effects arise with some 
argumental definites. All of the (a) examples in the following have a reading where it is implied that there are multiple satisfiers of the description following only. ${ }^{30}$

(80) a. Anna didn't give the only invited talk.

Anti-uniqueness reading: There was more than one invited talk (one of which Anna gave).

Determinate reading: There was exactly one invited talk (and Anna didn't give it).

b. Anna didn't see the only invited talk.

$\models$ There was exactly one invited talk.

(81) a. Mary didn't score the only goal.

Anti-uniqueness reading: There was more than one goal (one of which Mary scored).

Determinate reading: There was exactly one goal (which Mary did not score).

b. Mary didn't cheer for the only goal.

$\models$ There was exactly one goal.

The following examples exhibit analogous contrasts.

(82) a. Mary didn't bring the only chocolate cake.

b. Mary didn't taste the only chocolate cake.

(83) a. Mary didn't have the only beautiful dress there.

b. Mary didn't admire the only beautiful dress there.

On the primary reading of (80a), the speaker takes for granted that Anna gave an invited talk, and asserts that someone else gave an invited talk as well. In such a situation, there is no talk with the property 'only invited talk', so existence fails here. Let us delay the question of why anti-uniqueness readings come about in the (a) sentences but not the (b) sentences, and focus on the point that there are anti-uniqueness effects in argument position. This means that definite descriptions in argument position are not always associated with an existence presupposition.

Let us recap. So far, we have an account of predicative definite and indefinite descriptions which says that in each case the description simply denotes the same property as that given by the nominal. We now need a theory of how that description can be used to fill in an argument slot, and we need to account for the fact that sometimes there is an attendant presupposition of existence, and sometimes there is not.

\subsection{Two sources of existential import}

We propose that the meaning of NPs in argument position can be derived from an underlying property denotation in two ways: (i) application of IOTA, so that the description

30 Naturally-occurring examples of the kind in (80a) are not difficult to find, e.g.:

i. Taissa Farmiga didn't give the only great performance this episode; Evan Peters was outstanding.

ii. The state department of conservation doesn't run the only fish hatchery in the northwest suburbs.

iii. Bach didn't write the only music for solo violin. 
denotes the unique individual satisfying the description, giving a determinate interpretation; (ii) application of an existential type-shift EX, which introduces an existential quantifier, giving an indeterminate interpretation.

(84) Meaning shift: IOTA

IOTA $\equiv \lambda P . \iota x P(x)$

(85) Meaning shift: EX

$$
\mathrm{EX} \equiv \lambda P \cdot \lambda Q \cdot \exists x[P(x) \wedge Q(x)]
$$

The determinate interpretation of a definite NP of the form 'the $P$ ', with IOTA, is of type $e$, denoting the unique $P$. On the indeterminate interpretation, with EX, 'the $P$ ' is defined when $P$ satisfies weak uniqueness, and would denote a generalized quantifier that accepts a predicate $Q$ if its intersection with $Q$ is non-empty.

We define the $\iota$-operator in our logic so that it denotes a special 'undefined individual' if there fails to be exactly one satisfier of the predicate. We denote the undefined individual using $\#_{e}$, in the style of Haug (2013). ${ }^{31}$

(86) Semantic interpretation rule: $\iota$

$$
\llbracket \iota u \phi \rrbracket=d \text { if }\left\{x: \llbracket \phi \rrbracket^{M, w, g[u \rightarrow x]}=\mathrm{T}\right\}=\{d\} ; \#_{e} \text { otherwise. }
$$

This undefinedness will typically 'percolate up' through a sentence to yield the 'undefined' truth value. (See the appendix for details.) Thus $\iota$ presupposes existence and uniqueness in the sense that it yields the 'undefined' truth value when these are not satisfied, even though this cannot be read off the formula from $\partial$-terms.

For an example like (80b), IOTA applies, so the analysis would be as follows:

$$
\neg[\operatorname{SEE}(\operatorname{IOTA}(\mathrm{THE}(\mathrm{ONLY}(\mathrm{TALK}))))(\mathrm{A})]
$$

Here is the structure of the derivation:

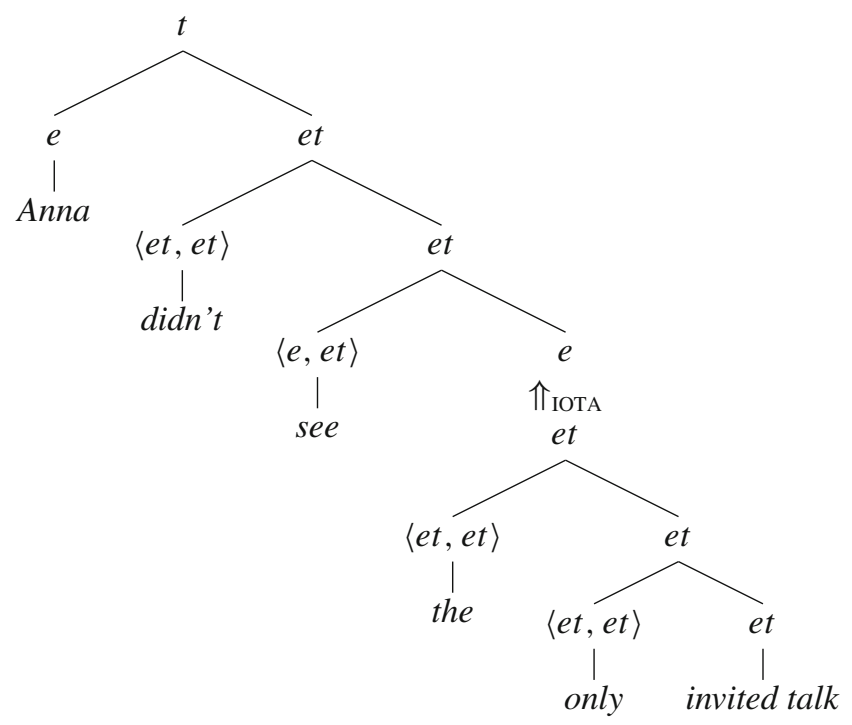

\footnotetext{
${ }^{31}$ Other notations that have been used for the undefined individual include Kaplan's (1977) $\dagger$, standing for a 'completely alien entity' not in the set of individuals, Landman's (2004) 0, and Oliver and Smiley's (2013) $O$, pronounced 'zilch'.
} 
This sentence will have the third truth value unless there is exactly one satisfier of the predicate only talk. This is the determinate reading.

But an example like (80a) also has an indeterminate reading, involving EX, which gives rise to the translation in (89):

$$
\neg \exists x[\operatorname{THE}(\operatorname{ONLY}(\operatorname{TALK}))(x) \wedge \operatorname{GIVE}(x)(\mathrm{A})]
$$

Ways to give the existential quantifier narrow scope with respect to negation include (i) Hendriks (1993)-style argument raising and (ii) combining the VP-internal subject hypothesis with the assumption that QR can target VP nodes as suggested in Heim and Kratzer (1998, p. 216ff). We illustrate the first strategy here, using the instantiation of Hendriks's (1993) Argument Raising rule in (92).

(90) Meaning shift: Object Raising

$$
\mathrm{OR} \equiv \lambda R \cdot \lambda v_{\langle e t, t\rangle} \cdot \lambda y \cdot v(\lambda z \cdot R(z)(y))
$$

This gives us a derivation tree that looks like this:

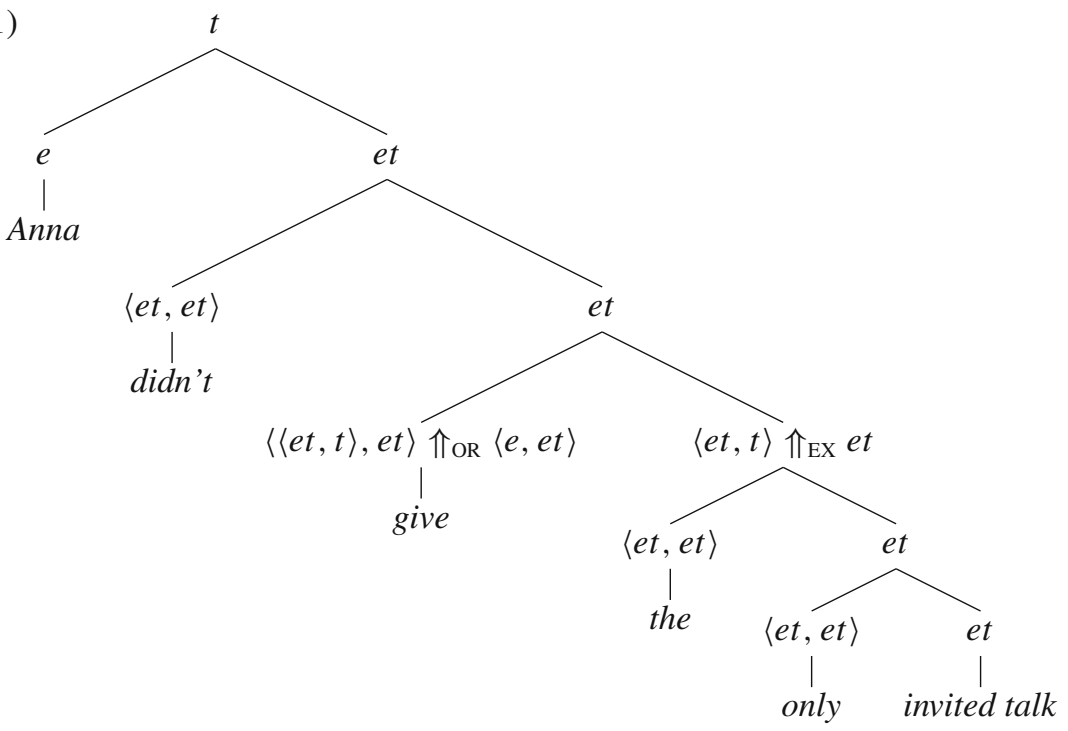

Expanding (89) reveals a trivial presupposition that there is at most one only talk:

(92) $\neg \exists x[\partial(|\operatorname{ONLY}(\mathrm{TALK})| \leq 1) \wedge \operatorname{ONLY}(\mathrm{TALK})(x) \wedge \operatorname{GIVE}(x)(\mathrm{A})]$

The trivial presupposition can be eliminated, giving:

(93) $\neg \exists x[\operatorname{ONLY}(\operatorname{TALK})(x) \wedge \operatorname{GIVE}(x)(\mathrm{A})]$

After expanding the meaning of ONLY, the logic we are using, IL3 (Three-valued Intensional Logic), defined in the Appendix, allows further simplifications ${ }^{32}$ producing the meaning in (94): it is presupposed that someone gave an invited talk, and at issue that some invited talk was not given by Anna.

32 The expanded meaning of (93) is $\neg \exists x[\partial(\operatorname{TALK}(x)) \wedge \forall y[x \neq y \rightarrow \neg \operatorname{TALK}(y)] \wedge \operatorname{GIVE}(x)(\mathrm{A})]$. The simplifications concern the fact that (89) has a negated, existentially bound presupposition. See the appendix (section introducing presuppositional properties). The equivalences proved there enable the presupposition to be separated from the negation and the quantifier. 


$$
\exists x \partial(\operatorname{TALK}(x)) \wedge \neg \exists x[\operatorname{TALK}(x) \wedge \forall y[x \neq y \rightarrow \neg \operatorname{TALK}(y)] \wedge \operatorname{GIVE}(x)(\mathrm{A})]
$$

Note that conjunction takes widest scope in (94), so the scope of the first existential quantifier ends with the first conjunct.

Thus it is correctly predicted that (80a) presupposes that there was an invited talk, without presupposing the existence of anything satisfying the description 'only invited talk'.

Intuitively, (80a) also presupposes that Anna gave an invited talk, on the antiuniqueness reading. We do not offer a formal account of this here, but we suggest that the inference is related to the placement of focus on only, and that the relevant alternative to only would be 'one of several' or 'multiple'. If the question is whether Anna gave only one talk or multiple talks, then it is common ground that she gave at least one. This reasoning assumes that there is at least one true alternative in the question under discussion, a principle that has been codified in various ways, including Geurts and van der Sandt's (2004) Background-Presupposition Rule, ("Whenever focus gives rise to a background $P$, there is a presupposition to the effect that $P$ holds of some individual"), Isaacs and Rawlins's (2008) exhaustivity constraint ("Every world in the context set makes some proposition in the QUD true"), and the first clause of Beaver and Clark's (2008) Current Question Rule ("The Current Question must contain at least one true alternative."). Adopting such a principle ought to ensure that it is taken to be common ground prior to interpretation of the sentence that either Anna gave the only invited talk, or she gave one of multiple talks.

\subsection{No determinate indefinites}

Our claim is that IOTA and EX are both generally available, and not inherently associated with definite descriptions in any way. In the absence of other considerations, this would predict that IOTA could apply to indefinites and yield determinate interpretations for indefinites. But due to the presence of other constraints, this turns out to be impossible under the present system.

In order for an IOTA shift to be applicable in a given context, existence and uniqueness have to be in the common ground. In general, the presuppositions of a sentence must be satisfied in a given context in order for the sentence to be felicitous. We implicitly gave a formal characterization of presupposition satisfaction above in connection with the definition of Maximize Presupposition, by saying what it means for an update to a context set to be defined. Building on Stalnaker (1978), Karttunen (1974), and Heim (1983), we can say that the presuppositions of a sentence are satisfied by a context set $C$ (a set of possible worlds) if $C+p$ is defined, where $p$ is the proposition corresponding to the sentence. Recall that $C+p$ is defined if $p$ is a function from worlds to truth values whose value is defined (i.e. classical) for all worlds in the context. Natural language sentences including descriptions that are interpreted with IOTA require existence and uniqueness to be satisfied in the common ground in this sense.

With this in mind, let us consider whether indefinites could ever be interpreted with an IOTA shift. We predict that this is not possible, given Maximize Presupposition. For example, take the following sentence:

(95) Every student saw a long film with Marlene Dietrich in it. 
Here we have a reading with every student taking scope over the indefinite, and in which the correct truth conditions obtain if the indefinite has existential force, i.e. an indeterminate reading. Assume that the hearer is not entirely certain as to what the speaker takes to be the discourse context, and in particular, whether existence and uniqueness are satisfied in it. The hearer can reason based on the choice of description: If uniqueness were satisfied in the common ground, then the speaker would have used the, by Maximize Presupposition. It follows that the discourse context does not entail existence and uniqueness, so the conditions for a determinate reading are not met. In general, whenever the article is indefinite, a determinate interpretation is impossible. ${ }^{33}$

\subsection{Preference for determinate interpretations}

Definite descriptions, unlike indefinite descriptions, can have both determinate and indeterminate interpretations. The reader may worry at this point that our analysis overgenerates indeterminate interpretations. Recall Elbourne's (2012) critique of Fara's (2001) proposal involving example (76), repeated here:

(96) a. It's possible that the ghost in Hans's attic is being noisy.

b. It's possible that there is exactly one ghost in Hans's attic and it is being noisy.

These two sentences have different uses. Whereas (96a) is naturally used by a speaker who takes there to be a ghost in Hans's attic (and is uncertain about the ghost's noisiness), (96b) does not imply that the speaker believes in ghosts, or even that the speaker takes some possibly non-actual ghost to be in the discourse context. Presumably, the reason is that (96a) does not have an easily accessible indeterminate reading comparable to that found for (96b). It is in that sense that an account which uniformly predicted the availability of indeterminate readings for definites could be said to overgenerate. In this section, we will propose a principle that derives a preference for determinate interpretations of descriptions in argument position. ${ }^{34}$

There are a number of factors complicating the reasoning surrounding (96), which we can avoid by taking the following variants:

(97) a. It's possible that the grandfather clock in Hans's attic is making a noise.

b. It's possible that there is a grandfather clock in Hans's attic and it is making a noise.

We have changed ghost to grandfather clock for two reasons. First, there is no a priori reason to believe that a speaker is considering a non-actual clock, i.e., a clock which has broad but not narrow existence, whereas there is an a priori reason to assume that with ghost. The difference between broad and narrow existence is not directly relevant to the point we're making here, so we'll stick with clocks.

\footnotetext{
33 As we discuss in Sect. 5, it would be interesting to consider the consequences of loosening this system so that certain indefinites - those called "specific" in particular-can receive a determinate interpretation.

34 The principle we will introduce has effects which are comparable to those achieved by Gendler Szabó's (2000) familiarity condition (p. 35): "For every definite description, if there is an appropriate old card in the file, update it; otherwise start a new card."
} 
Second, one typically has no more than one grandfather clock in any given attic, so weak uniqueness is plausibly satisfied in the context. This is connected to the change we have made in (97b), where we have there is a instead of there is exactly one. The problem with using there is exactly one is that it makes uniqueness at issue, and this is not a good representation of what the indeterminate reading would yield as a paraphrase. The indeterminate reading would retain the uniqueness presupposition of the definite article, and existence is what would potentially be at issue. Using an inherently unique description allows us to give a paraphrase involving an indefinite article that conveys the right meaning, and grandfather clock in Hans's attic approximates such an inherently unique description.

Now, let us observe that (97a) suggests that the speaker takes there to be a grandfather clock in Hans's attic (as would be predicted by an IOTA analysis), while (97b) does not. If, as we have allowed, indeterminate interpretations are freely available, then (97a) should have a reading on which it is equivalent to (97b).

Note that the choice between IOTA and EX interpretations only plays a role in cases of uncertainty about the common ground, in particular uncertainty as to whether the speaker presupposes existence or not. In contexts where existence is clearly presupposed, IOTA and EX readings will have the same effect. In contexts where existence is clearly not presupposed, IOTA readings are ruled out. The key observation here is that in a context where it is not clear whether the speaker presupposes existence, use of (97a) can be interpreted as a signal that he or she does. This suggests that there may be a preference for IOTA interpretations over EX interpretations in cases of uncertainty about the context.

There is a precedent for such a preference. As background, in his seminal paper on type-shifting and the interpretation of bare nominals, Chierchia (1998) argues for a principle according to which his 'nominalization' shift $U$ is ranked over what we refer to here as IOTA and EX, grounded in the notion of meaning preservation: since nominalization does not introduce existential import, and the other shifts do, it is more 'meaning-preserving'. Dayal (2004) then argues for a ranking principle on which $\cup$ and IOTA are both ranked above EX, justified on the grounds that the former two do not introduce quantificational force. We do not see $\cup$ as part of the same paradigm as IOTA and EX because nominalization operates on properties (type $\langle s, e t\rangle$ ) and IOTA and EX operate on predicates (type $\langle e, t\rangle$ ). However, the data we have just seen supports the Dayal (2004) proposal insofar as IOTA is ranked above EX. We assume that this preference is grounded in a general preference for simpler types like $e$ over more complex types like $\langle e t, t\rangle .{ }^{35}$ So, rather than 'Meaning Preservation', we will call the principle 'Type Simplicity'.

It is crucial to articulate the nature of this preference ranking carefully. It must not be so strong that it can lead hearers to give interpretations that are incompatible with what they know independently, but it must be sufficiently strong that it can lead hearers to accommodate the presuppositions of the favored interpretations. We formulate it as follows:

\footnotetext{
35 Assuming that quantified NPs must move to be interpreted, this preference might alternatively (or additionally) be cast as a kind of faithfulness constraint dispreferring LF movement, preferring interpretation in situ if possible.
} 


\section{(98) Principle: Type Simplicity}

Given a choice between two type-shifting operations, a hearer should choose the one resulting in the simpler type and accommodate any associated presuppositions if they are consistent with the available evidence as to what the speaker presupposes.

Notice that this principle will not predict a preference for determinate interpretations of predicative definites, because no type-shifting needs to take place for the interpretation of those. ${ }^{36}$ The principle will derive the contrast between (97a) and (97b), though: Assuming that there is no evidence to suggest that the speaker does not presuppose existence of a grandfather clock in Hans's attic, a hearer should adopt an IOTA interpretation and the associated existence presupposition. In the next section, we discuss some kinds of evidence regarding what the speaker presupposes that would be inconsistent with a determinate interpretation.

\subsection{Argumental anti-uniqueness effects}

Recall (80a), repeated here as (99a).

(99) a. Anna didn't give the only invited talk.

Anti-uniqueness reading: There was more than one invited talk (one of which Anna gave).

Determinate reading: There was exactly one invited talk (and Anna didn't give it).

b. Anna didn't see the only invited talk. $\models$ There was exactly one invited talk.

This data becomes more intricate once intonation is considered. In particular, when only receives nuclear stress (corresponding, presumably, to marking of narrow focus), the anti-uniqueness reading is the only one available for (99a), and becomes at least marginally available for (99b). In this section we will first describe how this effect of intonation can be predicted, and then describe how the difference between (99a) and (99b) can be accounted for in the absence of such a marked stress pattern.

Let us assume that when focus is on only in (99a), the alternatives are 'only' and 'multiple' as discussed above, and further assume Beaver and Clark (2008) Current Question Rule (or its second clause, to be precise), corresponding to what Roberts (1996) calls the 'non-triviality constraint':

\section{(100) Principle: Non-triviality of the Current Question}

The Current Question contains multiple alternatives which are not resolved as true or false in the common ground.

In (99a), there are only two alternatives, 'only' and 'multiple', so this principle requires that neither is resolved as true or false in the common ground. In particular, the common

\footnotetext{
36 To ensure that no type-shifting takes place in predicative cases, one might need to invoke the principle of 'type-shifting as a last resort' if BE is treated an allowable type-shift, but this is actually not necessary given our assumptions, because we do not include BE in our inventory of type-shifting operations, so we do not derive an interpretation of predicative definites involving IOTA no matter how many type-shifts apply.
} 
ground must allow for the possibility that Anna gave multiple talks. Existence of a unique invited talk therefore cannot be in the common ground. This constitutes evidence, in the sense of Type Simplicity, that the hearer should not take it to be given that the description (the) only invited talk has a non-empty extension. Given that the discourse context does not ensure existence of an appropriate entity, it follows that the conditions for the IOTA-shift are not met, and that a determinate interpretation is not available for (99a) when focus is placed on only. So IOTA is blocked from applying, making way for EX.

We now turn to the question of why the anti-uniqueness reading is preferred for (99a), and, more generally, the lexical semantic factors that lead to the availability of such readings. ${ }^{37}$ Above, in Sect. 3.1 (cf. also fn. 30), we noted that anti-uniqueness readings are available for objects of at least the following verbs: give (a talk), score (a goal), bring, run (an operation/business), write, and have. We suggest that what unifies these is that they allow existence to plausibly be at issue. The subclass of verbs for which this is perhaps most obviously the case is verbs of creation: give ( $a$ talk), score and write in the above list. ${ }^{38}$ Similar effects can be observed with other verbs of creation, including bake, paint (a picture), make, and build. Further, it is easy to construct minimal pairs of verbs which are similar in other respects, but differ in that only one is a verb of creation, and in such cases the anti-uniqueness reading is generally only available for the verb of creation. Thus, e.g. (101a) implies the existence of multiple decent papers, but, in the absence of further supporting context, (101b) does not:

(101) a. Mary didn't write the only decent paper.

b. Mary didn't read the only decent paper.

Other than verbs of creation, the list of anti-uniqueness verbs above contains bring, run, and have, to which we might add wear, find and own. We will now offer some diagnostics which suggest that all of these verbs, like verbs of creation, are used to introduce objects into the domain of discourse. Let us say that a verb $\mathrm{V}$ is an entityintroducing verb (in some frame, with some sense) if and only if "to V an N" tends to increase the number of salient Ns. Our first diagnostic, then, is that inferences involving this simple arithmetic inference are felicitous, and the following examples (in which the verb being tested is italicized) show how this may be applied:

There are at least seven cakes. If Maria brings a cake, that will make eight.

b. There are at least seven cakes. \#If Maria takes a cake, that will make eight.

\footnotetext{
37 The generalization we advocate here makes similar predictions to Coppock and Beaver (2012b) ' 1 -to-1 generalization', but connects more immediately to the principles governing the availability of indeterminate readings.

38 The class of intensional verbs like look for, seek, need and want (Moltmann 1997) has in common with this class that existence of the object at the beginning of the event is not required; the difference is that intensional verbs do not entail the existence of the object at all.
} 
(103) a. There are at least seven books. If Maria writes a book, that will make eight.

b. There are at least seven books. \#If Maria reads a book, that will make eight.

(104) a. There have been at least seven strapless dresses on the runway. If Maria wears a strapless dress, that will make eight.

b. There have been at least seven strapless dresses on the runway. \#If Maria likes a strapless dress, that will make eight.

(105) a. There are at least seven BMWs in the neighborhood. If Maria has a BMW, that will make eight.

b. There are at least seven BMWs in the neighborhood. \#If Maria cleans a BMW, that will make eight.

The above examples show that bring, write, wear, and has are entity-introducing verbs, but that take, read, like, and clean are not.

The reverse side of the same coin is that when an entity-introducing verb is under the scope of negation, there is no existence implication for an indefinite object argument, whereas for other verbs the implication tends to survive negation. This leads to patterns like the following, which provide evidence that the underlined verbs in the (a) examples (bake, paint, find, and run) are entity-introducing in these uses, while the underlined verbs in the (b) examples (taste, dislike, scratch, and oppose) are not.

(106) a. Nobody baked any brownies. \#Some of them are made with nuts.

b. Nobody tasted any brownies. Some of them are made with nuts.

(107) a. Nobody painted any pictures. \#They were landscapes.

b. Nobody disliked any pictures. They were landscapes.

(108) a. Nobody found any foreign cars. \#All of them were made in Italy.

b. Nobody scratched any foreign cars. All of them were made in Italy.

(109) a. Nobody ran any businesses. \#They were well-established and profitable.

b. Nobody opposed any businesses. They were well-established and profitable.

The diagnostics in (102)-(109) provide evidence as to the degree to which a verb can felicitously be used to introduce new entities. To put this in terms of the Type Simplicity principle, the diagnostics illustrate the degree to which use of a verb provides evidence preventing the hearer from taking the preconditions for a determinate interpretation to be met.

Note that this is not a purely lexical property. For example, the verb see does not introduce entities in the frame see a talk, but it can be used as an entity-introducing verb. Imagine a bird-watching expedition, and the participants are keeping track of how many birds have been seen. The following would be felicitous in that context:

(110) If John sees a sparrow, that will make eight. 
And we find anti-uniqueness readings with see in this sense as well ${ }^{39}$ :

(111) He indeed saw that sparrow. But he didn't see the only sparrow-Sue had seen another one earlier!

So see is flexible with respect to its entity-introducing status.

Our claim is that the stronger the tendency of a verb (in a given sense) to introduce entities in a given position, the greater the availability of indeterminate readings when the relevant argument is of the form the only $N$. Conversely, the weaker the tendency of a verb (in a given sense) to introduce entities in a given position, the greater the tendency for such arguments to yield determinate readings, with no anti-uniqueness effects. This is borne out by the contrasts we have just seen. The existence of such tendencies also bears on the fact that for verbs which are not entity introducers, antiuniqueness readings remain marginal even with stress on only: we suggest that for some speakers, the tendency of some verbs not to be used to introduce entities is sufficiently strong that even focal stress cannot override it.

Let us summarize. Together with Maximize Presupposition, the Type Simplicity principle implies an important difference between the inferences associated with indefinite and definite descriptions occurring in argument positions. Even when a definite description occurs in an embedded position (e.g. under a possibility operator or negation), global implications of existence and uniqueness will follow. In such a case, the meaning is always determinate, with the meaning being derivable using an IOTA-shift. For indefinites, on the other hand, Maximize Presupposition implies that uniqueness is not satisfied, and IOTA cannot apply. In such a case, only an indeterminate reading, generated by type-raising with EX, is possible. Hence argumental uses of the are typically determinate and associated with presuppositions of existence and uniqueness, while argumental uses of $a$, while they may or may not be associated with an existence presupposition, are indeterminate, and do not yield a uniqueness presupposition.

\section{Possessives}

In this section, we will demonstrate the generality of the concepts 'determinate' and 'indeterminate' by arguing that possessive descriptions, like definite descriptions, can be either. The possessive noun phrases we are focussing on are those that begin with a genitival noun phrase or a possessive pronoun ("Saxon genitives"). We will refer to these as "possessive descriptions", or "possessives" for short, such as Mary's mother, at least one child's pet rabbit(s), everyone's grandmother, and my former roommate's father's law firm.

As Peters and Westerståhl (2013) discuss, it is often suggested that possessive descriptions contain a hidden the. For example, Partee and Borschev (2003, fn. 6) say 'the prenominal genitive in English seems to combine the 'basic' genitive [the post-nominal form] with an implicit definite article." Vikner and Jensen (2002, p. 201) say that a possessive "behaves as if it had an implicit definite article... associated with [the possessed noun]". Kamp (2001, p. 220) analyzes possessives using a null definite

39 Thanks to a reviewer for this example and the related point. 
determiner preceding the overt possessive pronoun. In contrast, Peters and Westerståhl (2013) argue emphatically that possessives are not definite.

Our position is in the middle. We will argue that possessives are not exactly like definites, and not exactly like indefinites, although all three are subject to the same inventory of shifting operations and are fundamentally predicative. Possessives, unlike definites, do not encode a weak uniqueness presupposition, as we can see from predicative uses. Unlike the indefinite article, however, Saxon genitives like John's are not classically equivalent to the definite article, so they do not compete with it under Maximize Presupposition. Therefore, possessives have determinate readings; in fact, due to the preference for simpler types, this is the usual case. We may summarize our position as follows: possessive descriptions are not marked for definiteness, but are typically determinate.

\subsection{Presuppositions of possessives}

One prima facie reason for believing that possessives are definite is that possessive descriptions with definite possessors in argument position typically behave like (constant) terms, i.e., behave as if they have denotations of type $e$. Löbner (2011), building on Löbner (1985) i.a., gives two tests for when an expression behaves as if it has a denotation of type $e$ :

(112) Negation test

a. Mary's pet rabbit is in the cage and Mary's pet rabbit is outside the cage. (contradictory)

b. Some rabbit is in the cage and some rabbit is outside the cage. (not contradictory)

(113) Conjunction test

a. Mary's pet rabbit is from South Africa and Mary's pet rabbit is a secret agent.

$\equiv$ Mary's pet rabbit is a secret agent from South Africa.

b. Some rabbit is from South Africa and some rabbit is a secret agent.

$\not \equiv$ Some rabbit is a secret agent from South Africa.

The 'negation test' illustrated in (112) is based on the observation that if NP denotes an individual, then 'NP VP' should be false if and only if 'NP $\neg$ VP' is true, where $\neg$ represents predicate negation. As a consequence, 'NP VP and NP $\neg$ VP' should be contradictory (cf. Heim and Kratzer's 1998 test involving the Law of Contradiction, pp. 133-134). The 'conjunction test' illustrated in (113) is based on the observation that ' $\mathrm{NP}\left[\mathrm{VP}_{1}\right.$ and $\mathrm{VP}_{2}$ ]' should be true if and only if ' $\mathrm{NP} \mathrm{VP}_{1}$ ' is true and ' $\mathrm{NP} \mathrm{VP}_{2}$ ' is true (on a purely conjunctive reading of and), if NP denotes an individual. As shown in (112) and (113), possessives with definite possessors come out as definite according to these criteria, in contrast to, for example, some phrases.

The same tests applied to predicative expressions produce striking results. Compare the behavior of predicative possessives in (114a) and (115a) with that of predicative 
indefinite descriptions in (114b) and (115b), and predicative definite descriptions in $(114 c)$ and (115c):

(114) Negation test (Predicative)

a. The rabbit in the cage is Mary's pet and the rabbit sitting just outside the cage is Mary's pet. (not contradictory)

b. The rabbit in the cage is a pet Mary owns and the rabbit sitting just outside the cage is a pet Mary owns. (not contradictory)

c. The rabbit in the cage is the pet Mary owns and the rabbit sitting just outside the cage is the pet Mary owns. (contradictory)

(115) Conjunction test (Predicative)

a. The rabbit from South Africa is Mary's pet and the Indonesian cat is Mary's pet.

$\not \equiv$ Mary has a South African pet rabbit which is also an Indonesian cat.

b. The rabbit from South Africa is a pet Mary owns and the Indonesian cat is a pet Mary owns.

$\not \equiv$ Mary has a South African pet rabbit which is also an Indonesian cat.

c. The rabbit from South Africa is the pet Mary owns and the Indonesian cat is the pet Mary owns.

$\equiv$ Mary has a South African pet rabbit which is also an Indonesian cat.

A number of conclusions can be drawn from the paradigms in (114) and (115). First, although we analyze predicative definites as denoting properties, they behave in the same way as terms in these tests. It might be said that Löbner's tests are diagnostic of the unicity of the extension of an expression, rather than providing direct evidence for an individual denotation. Second, the paradigm shows that predicative possessives pattern with predicative indefinites rather than predicative definites. Thus predicative possessives lack uniqueness requirements.

The following examples again show that predicative possessives lack the uniqueness requirements of the:

(116) a. Is that your bicycle?

b. Is that the bicycle you own?

Example (116a) does not presuppose that the hearer has only one bicycle. A felicitous reply would be:

(117) Yes, and that one there is also mine.

But (117) would not be a felicitous reply to (116b). Consider also the following contrasts.

(118) a. This is the state's property, and so is that.

b. \#This is the property that the state owns, and so is that. 
(119) a. This is Jane's work, and so is that.

b. \#This is the work that Jane did, and so is that.

Examples like (116a) and (116b) are complicated somewhat by the fact that the copula can be interpreted either equatively or predicatively. Under the equative reading, a determinate reading is predicted to be available. This could lead to intuitions that (116a) actually does have a uniqueness implication; in other words, a uniqueness implication could arise through interference from an equative reading. One way of guarding against this is to insert modifiers that are incompatible with the equative reading such as to some extent and $100 \%$ :

(120) Trotsky is $100 \%$ the king's horse/\#Superman\}.

(121) Trotsky is to some extent $\{$ the king's horse/\#Superman $\}$.

With these modifiers, there is clearly no uniqueness implication with the possessive; the king may well have multiple horses. Furthermore, when conjoined with unambiguously predicative expressions, possessive expressions do not give rise to a uniqueness implication:

(122) He is tall, dark, handsome, and my cousin (alas!).

It is possible for the speaker to have multiple cousins in (122). Furthermore, the consider construction is unambiguously predicate-taking, so there should not be any uniqueness implication at all in these kinds of constructions if possessives do not contain a hidden the. That prediction appears to be borne out.

(123) a. I consider this your problem.

b. I consider this the problem you have.

Whereas (123b) conveys that the addressee has only one problem, (123a) does not. This contrast can be brought out by considering the continuation, “... and here is another problem you have: ...", which would be felicitous after (123a) but not (123b).

We conclude that possessive descriptions are not inherently definite in the sense that they do not encode a weak uniqueness presupposition, despite the fact that (in argument positions) they are typically determinate and thus behave like terms. ${ }^{40}$

Of course, logically it could be the case that although predicative possessives lack any uniqueness presupposition, they do have an existence presupposition. This is not the case. Returning to a now familiar type of data, consider example (124), which on a natural reading implies John made multiple contributions. This shows that predicative possessives manifest anti-uniqueness effects, and hence provides evidence that they lack an existence presupposition.

(124) That wasn't John's only contribution.

\footnotetext{
40 We can also find evidence for a lack of a lexically specified uniqueness requirement from examples involving plurals, e.g. This artist has had enormous success. Her paintings are in the Louvre, her paintings are in the National Gallery, her paintings are everywhere! But accounting for this would require us to go into the details of the analysis of plurals, which we do not have space for in this article.
} 
Examples (125) and (126) further support the absence of existence presuppositions for predicative possessives. Example (125) does not imply that anything was Mary's fault, and (126) does not imply that speaker B owns an eighteen-wheeler. Note here that nothing in the context of these examples logically implies that Mary is not in some way at fault, or that speaker B lacks an eighteen-wheeler, so if there were an existence presupposition there would be no reason to expect it to be canceled.

(125) That wasn't Mary's fault!

(126) A: Is that your eighteen-wheeler that's blocking the entrance? B: No!

The data in this section supports the view that possessive descriptions do not come with a hidden definite: possessive morphology encodes neither existence nor uniqueness. This then leaves a puzzle: how can it be that predicative possessives are not definite when argumental possessives pass standard tests for determinacy? In other frameworks, such data would seem to imply that predicative possessives and argumental possessives have underlyingly very different lexical semantics, but, of course, in the current framework there is no need to postulate such an ambiguity: the availability of IOTA and the Type Simplicity principle provide a strategy for accounting for the facts without postulating any lexical definiteness requirement, and without postulating any lexical ambiguity.

\subsection{Derivation of determinate readings for possessives}

Let us take the example Trotsky is the king's horse. Inspired by Barker (1995), we adopt the following structure for the king's horse:

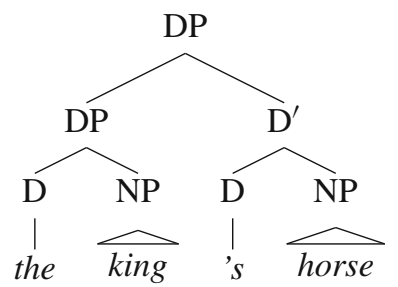

Following Vikner and Jensen (2002), we assume that possessive 's forces horse to undergo a type-shift to a relational noun. We assume in particular that possessive 's itself is just an identity function on relational nouns, so that if a relational noun like mother comes in as an argument, the possessive construction does nothing to change it:

$$
\text { 's } \rightsquigarrow \lambda R_{\langle e, e t\rangle} \cdot R
$$

Note that the lexical semantics we propose for possessives is original: while our analysis of the genitive as creating a type requirement follows Vikner and Jensen (2002), it differs from theirs in that for them the genitive encodes definiteness, whereas for us the genitive contributes no content at all beyond its type restriction, and definiteness is derived by a separate type shift.

An $\langle e, t\rangle$-type noun can be shifted into a relational noun with the following shift, which we are calling $\mathrm{R}$. 
(129) Meaning shift: Sortal to relational noun

$\mathrm{R} \equiv \lambda P \cdot \lambda y \cdot \lambda x \cdot[P(x) \wedge \operatorname{POSS}(x)(y)]$

This yields $\lambda y \cdot \lambda x$. [HORSE $(x) \wedge \operatorname{POSS}(x)(y)]$ for horse. The possessor the king goes in for the possessor argument and out comes the property of being a horse owned by the king:

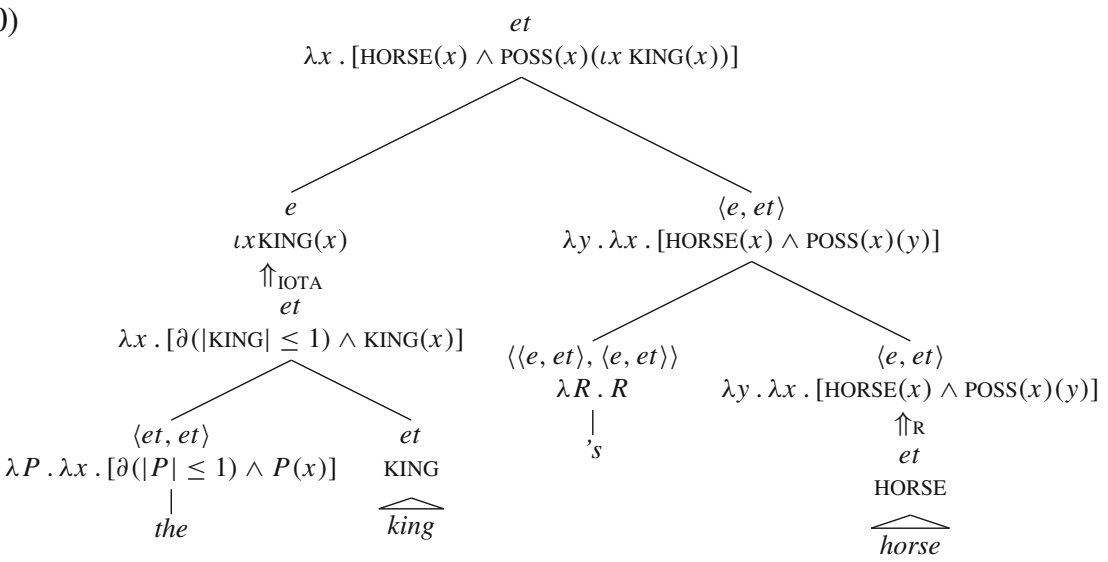

The details of the syntax of possessives are not crucial here; what is crucial is that possessives are not inherently definite, and fundamentally denote predicates that can in principle be shifted with either IOTA or EX.

\subsection{Determinate and indeterminate readings of possessives}

Given what we have said so far, we would expect that argumental possessives can also receive both determinate and indeterminate readings. The latter are not expected to be common, due to the preference for determinate readings, but one place where they should be found is in the same kinds of environments where definites give rise to anti-uniqueness effects, namely with exclusives.

We showed above with (124) that anti-uniqueness effects arise with predicative uses of possessives. This does not show that they have indeterminate readings, because we assume that predicative uses do not involve any meaning shifts at all, just direct application of the predicate to the subject. But crucially, anti-uniqueness effects also arise with possessives in argument position. Here are two attested examples:

(131) Green card holders don't just take from the USA, nor do they make their only contribution through taxes.

(Implies green card holders make multiple contributions.)

(132) The Grinch didn't make his only appearance when he attempted to steal Christmas. Dr. Seuss reprised the character in two more books: ...

(Implies The Grinch made multiple appearances.)

Note that both of these examples involve frames for the verb make, a verb of creation, which, as argued above, have a tendency to bias against determinate readings. In (131), 
it is implied that there is no satisfier of the description 'their only contribution', since there are multiple contributions, which means that the IOTA shift cannot have applied. Likewise, in (132), there is no referent for 'his only appearance', since there were multiple appearances. This is inconsistent with an IOTA analysis. So possessives, like definite descriptions, can be interpreted indeterminately in argument positions.

We can capture the meaning of these examples in a parallel fashion to that by which we analyzed anti-uniqueness effects with definite descriptions, using EX. Let us consider (132). All of the action lies in the phrase make his only appearance, so we can focus on that. ${ }^{41}$

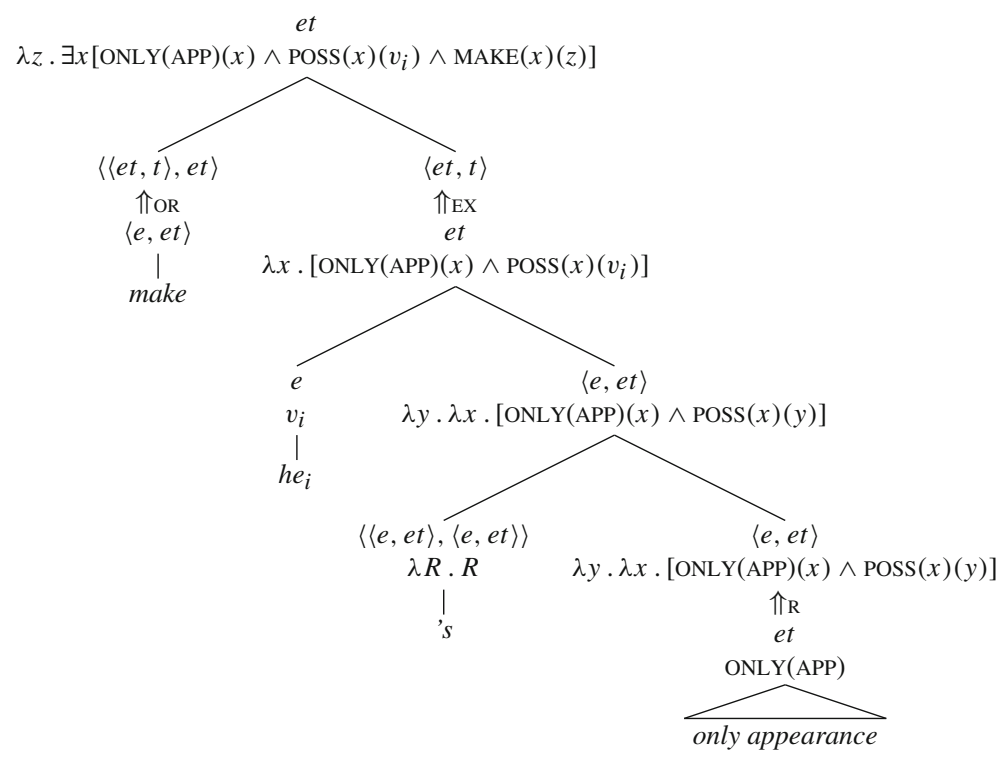

After negation applies and the subject goes in for $z$, the resulting meaning is (ignoring how the subject and the possessive pronoun get co-indexed):

$$
\neg \exists x\left[\mathrm{ONLY}(\mathrm{APP})(x) \wedge \operatorname{POSS}(x)\left(v_{i}\right) \wedge \operatorname{MAKE}(x)(\mathrm{G})\right]
$$

This correctly predicts that there were multiple appearances.

Note that the fact that possessives can combine with adjectival only suggests that our explanation for the impossibility of *an only problem was on the right track: It is not that adjectival only requires a definite determiner, or one that has a weak uniqueness presupposition; rather, the indefinite article is blocked by the definite article via Maximize Presupposition. Since possessives do not compete with the definite article, they are not blocked by it.

To summarize: Possessive descriptions, like all descriptions, can be interpreted with IOTA (preferably) or EX (when there is evidence that existence or uniqueness is not satisfied in the discourse context). Unlike indefinite descriptions, they do not compete with the definite article, and therefore typically have determinate interpretations.

$\overline{41}$ The pronoun is interpreted using the Pronouns and Traces Rule (see Appendix). 
Unlike definite descriptions, they do not come with a weak uniqueness presupposition, and therefore do not signal uniqueness when used predicatively.

\section{Summary and outlook}

We have argued that definite, indefinite, and possessive descriptions are underlyingly predicative and fill in argument roles through shifting operations. Descriptions can be interpreted either determinately (with the IOTA-shift) or indeterminately (with the EXshift). The IOTA-shift blocks the EX-shift in the absence of evidence to the contrary, and Maximize Presupposition ensures that the is chosen over $a$ whenever weak uniqueness is satisfied. This picture is summarized in Table 3. A fragment for English can be found in the Appendix.

The principles regulating shifting operations should not be specific to English if they are, as we have suggested, grounded in functional principles. We would therefore expect them to be operative in other languages as well. In languages without overt determiners, indeterminate readings for bare nominals should be available at least wherever indeterminate readings for definite descriptions are available in English. Preliminary evidence from Croatian (for which we thank Rajka Smiljanic) supports this prediction:

(135) Rajka nije bila jedini predavač: Megan je isto održala predavanje.

'Rajka was not the only speaker: Megan also gave a talk'

Bare nominals should have indeterminate interpretations under a greater range of circumstances than definite descriptions in English, though, because they are not subject to Maximize Presupposition, and this is the case, as shown by the first example in our paper. A fuller investigation of the ramifications of these ideas for article-less languages should be carried out in future work.

An issue relevant even for English that we have not dealt with fully is so-called "incomplete descriptions" like the cat, which of course do not presuppose that there is exactly one cat in the entire universe. Uniqueness must be somehow relativized to salience, as many authors have discussed (see Elbourne 2012 for an overview). We believe that there are a number of ways of taking salience into account which are consistent with our fundamental distinction between determinate and indeterminate readings, for example by relativizing the presupposition of the, the IOTA shift (and possibly EX too) to contextually restricted domains. A related issue is how indefinites

Table 3 Typology of interpretations for descriptions

\begin{tabular}{llll}
\hline & Predicative & Indeterminate & Determinate \\
\hline$a(n)$ & $P$ & $\operatorname{EX}(P)$ & - \\
the & $\lambda x \cdot[\partial(|P| \leq 1) \wedge P(x)]$ & $\operatorname{EX}(\lambda x \cdot[\partial(|P| \leq 1) \wedge P(x)])$ & $\operatorname{IOTA}(P)$ \\
$p^{\prime} s$ & $\lambda x \cdot R(x, p)$ & $\operatorname{EX}(\lambda x \cdot R(x, p))$ & $\operatorname{IOTA}(\lambda x \cdot R(x, p))$ \\
\hline
\end{tabular}


introduce discourse referents and how definites pick them up; in future work we hope to offer a dynamic version of our proposal. ${ }^{42}$

Yet another question for future research is whether indefinites can ever have readings that might be called 'determinate'. According to the way we have set things up, indefinites like a talk never get interpreted with IOTA, because of Maximize Presupposition. Assuming that $a$ and the compete, and that they both have vacuous ordinary semantic content, but the presupposes uniqueness, one should choose the whenever uniqueness holds in the context. The IOTA shift can only be applied when uniqueness holds in the context, so it will never be applied when $a$ was chosen over the. But what if indefinites can in fact undergo something like an IOTA shift, and what if this phenomenon is what has gone under the name of 'specific indefinites'? One possible way of working this out is to construe IOTA as a special case of Hilbert's $\epsilon$ operator (used directly or indirectly by e.g. Reinhart 1997; von Heusinger 1997; Winter 2001, i.a.), and use an $\epsilon$-shift defined in a way that ends up as equivalent to our IOTA shift when combined with a weak uniqueness presupposition.

To conclude, let us summarize the picture that we have developed at a high level, without reference to the details of the technical implementation. There is a distinction between definiteness and determinacy. Definiteness in English is the marking of weak uniqueness, uniqueness of a kind that is independent of existence, while determinacy is the property a description has when it picks out an individual in a given context. Thus, what makes the definite is its weak uniqueness presupposition. But it does not thereby follow that definite descriptions are always determinate. Predicative definite descriptions have no existence implication at all, and are therefore neither determinate nor indeterminate. In argument position, on the other hand, definite descriptions can be determinate (as in Anna didn't see the only invited talk), or indeterminate (as in Anna didn't give the only invited talk). By contrast with the, we have argued that the Saxon genitive 's in possessive descriptions does not mark definiteness at all, although this fact is masked in argumental uses of possessives, which are usually determinate. We have argued that definite, indefinite, and possessive descriptions all acquire existential import in argument position through shifting operations, and in the case of possessive descriptions this process is also the source of the uniqueness presuppositions which are associated with them. These shifting operations are independently motivated on the basis of other linguistic phenomena, including languages that lack definiteness-marking. The principles regulating their application, furthermore, are also quite general and could be universals grounded in fundamental principles of communication.

Acknowledgments We thank Dag Haug, Reinhard Muskens, Luca Crnič, Cleo Condoravdi, Lucas Champollion, Stanley Peters, Roger Levy, Craige Roberts, Bert LeBruyn, Robin Cooper, Hans Kamp, Sebastian Löbner, Francois Recanati, Dan Giberman, Benjamin Schnieder, Rajka Smiljanic, Ede Zimmerman, as well as audiences at SALT 22 in Chicago, IATL 29 in Jerusalem, Going Heim in Connecticut, the Workshop on Bare Nominals and Non-Standard Definites in Utrecht, the University of Cambridge, the University of

\footnotetext{
42 We presented a sketch of such a dynamic analysis at the Going Heim workshop at the University of Connecticut in 2015. There we argued that if a weak uniqueness presupposition was maintained as the sole semantic contribution of the definite article, and the indefinite remained semantically trivial, the novelty and familiarity presuppositions of Heim (1982) could be derived in a dynamic setting.
} 
Gothenburg, the University of Konstanz, New York University, the University of Oxford, Rutgers University, the University of Southern California, Stanford University, and the University of Texas at Austin. Beaver was supported by NSF grants BCS-0952862 and BCS-1452663. Coppock was supported by Swedish Research Council project 2009-1569 and Riksbankens Jubileumsfond's Pro Futura Scientia program, administered through the Swedish Collegium for Advanced Study.

Open Access This article is distributed under the terms of the Creative Commons Attribution 4.0 International License (http://creativecommons.org/licenses/by/4.0/), which permits unrestricted use, distribution, and reproduction in any medium, provided you give appropriate credit to the original author(s) and the source, provide a link to the Creative Commons license, and indicate if changes were made.

\section{A Appendix: Fragment of English}

\section{A.1 Three-valued Intensional Logic (IL3)}

We translate expressions of English to a logical representation language IL3, a threevalued variant of Montague's Intensional Logic.

Types. We have two basic types $e$ and $t$. If $\sigma$ and $\tau$ are types, then $\langle\sigma, \tau\rangle$ is a type. Each expression is associated with a type; an expression of type $t$ is called a formula.

Syntax of IL3.

SYN1 For each natural number $n, c_{n, \tau}$ is a non-logical constant of type $\tau$. We will use some shorthands for constants as well:

(a) $\mathrm{A}$ is $c_{0, e}$, $\mathrm{B}$ is $c_{1, e} \ldots$

(b) MOON is $c_{0,\langle e, t\rangle}$, TALK is $c_{1,\langle e, t\rangle}$, TEACHER is $c_{1,\langle e, t\rangle}, \ldots$

(c) GIVE is $c_{0,\langle e,\langle e, t\rangle\rangle}$, SEE is $c_{1,\langle e,\langle e, t\rangle\rangle}$, AUTHOR is $c_{2,\langle e,\langle e, t\rangle\rangle}$, POSS is $c_{3,\langle e,\langle e, t\rangle\rangle, \ldots}$

SYN2 For each natural number $n, v_{n, \tau}$ is a variable of type $\tau$. We will use the following shorthands for variables:

(a) $x$ is $v_{0, e}, y$ is $v_{1, e}$ and $z$ is $v_{2, e}$

(b) $P$ is $v_{0,\langle e, t\rangle}$ and $Q$ is $v_{1,\langle e, t\rangle}$

(c) $R$ is $v_{0,\langle e,\langle e, t\rangle\rangle}$

SYN3 If $\alpha$ is an expression of type $\langle\sigma, \tau\rangle$ and $\beta$ is an expression of type $\sigma$, then $\alpha(\beta)$ is an expression of type $\tau$.

SYN4 If $\alpha$ is an expression of type $\tau$ and $u$ is a variable of type $\sigma$, then $[\lambda u . \alpha]$ is an expression of type $\langle\sigma, \tau\rangle$.

SYN5 If $\phi$ is a formula and $u$ is a variable of type $\tau$, then $\iota u \phi$ is an expression of type $\tau$

SYN6 If $\alpha$ is an expression of type $e$, then $\operatorname{ACTUAL}(\alpha)$ is a formula.

SYN7 If $\alpha$ and $\beta$ are expressions of the same type, then $\alpha=\beta$ is a formula.

SYN8 If $\phi$ and $\psi$ are formulas, then so are $[\phi \wedge \psi]$ and $[\phi \vee \psi]$.

SYN9 If $\phi$ is a formula, then so are $\neg \phi, \partial \phi, A \phi$, and $C \phi$. For ease of parsing, $\partial \phi$ is usually rendered as $\partial(\phi)$.

SYN10 If $\phi$ is a formula and $u$ is a variable of type $\tau$, then $\forall u \phi$ is a formula.

SYN11 For all types $\tau, \star_{\tau}$ is an expression of type $\tau$. 
Further logical constants (including the existential quantifier and $\rightarrow$ ) will be defined via syntactic equivalences below.

Outermost square brackets can be deleted, as can brackets surrounding a lambda abstraction that serves as the value of another lambda abstraction, so $\lambda x . \lambda y . \phi$ is a shorthand for $[\lambda x .[\lambda y . \phi]]$.

Semantics of IL3. Types are associated with domains. Type $e$ is associated with the domain of individuals $D_{e}$ and type $t$ is associated with the domain of truth values $D_{t}$. For functional types $\langle\sigma, \tau\rangle$, there is a domain $D_{\langle\sigma, \tau\rangle}$ consisting of the (total) functions from $D_{\sigma}$ to $D_{\tau}$, including 'undefined individual' of that type, which we refer to as \# $\# \sigma \sigma \tau\rangle$. (See Haug 2013 for a principled construction of the undefined element for each type.)

Expressions are interpreted with respect to a model, a world, and an assignment. A model is a tuple $\left\langle D_{e}, D_{t}, W, I\right\rangle$ subject to the following constraints:

- The domain of individuals $D_{e}$ contains at least one individual along with the undefined individual of type $e$, denoted by $\# e^{43}$

- The domain of truth values $D_{t}$ contains three truth values: T, F, and \#. We use \# as a shorthand for \#.

- $W$ contains at least one possible world.

- $I$ is an interpretation function, assigning an intension to all of the constants of the language. The intension of a constant of type $\tau$ is a function from $W$ to $D_{\tau}$.

An assignment $g$ is a total function whose domain consists of the variables of the language such that if $u$ is a variable of type $\tau$ then $g(u) \in D_{\tau}$. We use $g[x \rightarrow d]$ to denote an assignment function which is exactly like $g$ with the possible exception that $g(x)=d$.

As expressions are interpreted with respect to a world of evaluation, all expressions have intensions relative to a given model and assignment function. Relative to a model $M$ and an assignment function $g$, the intension of an expression $\alpha$ is a function $f$ such that for any world $w, f(w)=\llbracket \alpha \rrbracket^{M, w, g}$. The intension of a sentence is the proposition that it expresses. (We imagine this proposition to play an important role in the pragmatics of presupposition and assertion, not formalized here but conceived of as in Beaver and Krahmer 2001, where the update proceeds pointwise with respect to the worlds in the context set.)

Expressions are interpreted according to the following rules. The superscripts $M$, $w$, and $g$ are sometimes suppressed.

SEM1 If $\alpha$ is a constant, then $\llbracket \alpha \rrbracket^{M, w, g}=I(\alpha)(w)$.

SEM2 If $u$ is a variable, then $\llbracket u \rrbracket^{M, w, g}=g(u)$.

SEM3 If $\alpha$ is of type $\langle\sigma, \tau\rangle$ and $\beta$ is of type $\sigma$, then $\llbracket \alpha(\beta) \rrbracket=\llbracket \alpha \rrbracket(\llbracket \beta \rrbracket){ }^{44}$

\footnotetext{
43 As mentioned above, other notations that have been used for the undefined individual include Kaplan's (1977) $\dagger$, standing for a 'completely alien entity' not in the set of individuals, Landman's (2004) 0, and Oliver and Smiley's (2013) $O$, pronounced 'zilch'.

44 This allows for the possibility of predicates that yield true or false given undefined inputs (such as ACTUAL), but we assume that predicates will typically be undefined for undefined inputs.
} 
Table 4 Interpretation of the connectives (Weak Kleene)

\begin{tabular}{|c|c|c|c|c|c|c|c|c|c|c|c|c|c|c|c|}
\hline$\wedge$ & $\mathrm{T}$ & $\mathrm{F}$ & \# & $\vee$ & $\mathrm{T}$ & $\mathrm{F}$ & \# & & $\neg$ & & $\partial$ & & $A$ & & $C$ \\
\hline $\mathrm{T}$ & $\mathrm{T}$ & $\mathrm{F}$ & \# & $\mathrm{T}$ & $\mathrm{T}$ & $\mathrm{T}$ & $\#$ & $\mathrm{~T}$ & $\mathrm{~F}$ & $\mathrm{~T}$ & $\mathrm{~T}$ & $\mathrm{~T}$ & $\mathrm{~T}$ & $\mathrm{~T}$ & $\mathrm{~T}$ \\
\hline $\mathrm{F}$ & $\mathrm{F}$ & $\mathrm{F}$ & \# & $\mathrm{F}$ & $\mathrm{T}$ & $\mathrm{F}$ & $\#$ & $\mathrm{~F}$ & $\mathrm{~T}$ & $\mathrm{~F}$ & \# & $\mathrm{F}$ & $\mathrm{F}$ & $\mathrm{F}$ & $\mathrm{T}$ \\
\hline \# & \# & \# & \# & \# & $\#$ & \# & \# & $\#$ & \# & \# & \# & $\#$ & $\mathrm{~F}$ & \# & $\mathrm{F}$ \\
\hline
\end{tabular}

SEM4 If $u$ is a variable of type $\tau$ then $\llbracket \lambda u \cdot \alpha \rrbracket^{M, w, g}=$ the function $f$ such that for all $d: f(d)=\llbracket \alpha \rrbracket^{M, w, g[x \rightarrow d]}$

SEM5 $\llbracket \iota u \phi \rrbracket^{M, w, g}=d$ if $\left\{x: \llbracket \phi \rrbracket^{M, w, g[u \rightarrow x]}=\mathrm{T}\right\}=\{d\}$; \# \# $_{e}$ otherwise.

SEM6 $\llbracket \operatorname{ACTUAL}(\alpha) \rrbracket=\mathrm{T}$ if $\llbracket \alpha \rrbracket \neq \#_{e}$ and $\mathrm{F}$ otherwise.

SEM7 $\llbracket \alpha=\beta \rrbracket=\mathrm{T}$ if $\llbracket \alpha \rrbracket=\llbracket \beta \rrbracket$ and $\mathrm{F}$ otherwise.

SEM8 If $\phi$ and $\psi$ are formulas, then $\llbracket \phi \wedge \psi \rrbracket$ and $\llbracket \phi \vee \psi \rrbracket$ are defined as in Table 4. These are the 'Weak Kleene' interpretations of the connectives, according to which \# is interpreted as 'nonsense'. 45

SEM9 If $\phi$ is a formula, then $\neg \phi \rrbracket, \llbracket \partial \phi \rrbracket, \llbracket A \phi \rrbracket$, and $\llbracket C \phi \rrbracket$ are defined as in Table 4. ( $\partial \phi$ can be glossed as 'presupposing $\phi$ '; $A \phi$ as 'assert $\phi$ ' and $C \phi$ as ' $\phi$ is classical')

SEM10 If $u$ is a variable of type $\tau$ and $\phi$ is a formula then:

$$
\llbracket \forall u \phi \rrbracket^{M, w, g}=\left\{\begin{array}{l}
\# \text { if for all } d \in D_{\tau}: \llbracket \phi \rrbracket^{M, w, g[u \rightarrow d]}=\# \\
\mathrm{~F} \text { if there is a } d \in D_{\tau}: \llbracket \phi \rrbracket^{M, w, g[u \rightarrow d]}=\mathrm{F} \\
\mathrm{T} \text { otherwise }
\end{array}\right.
$$

SEM11 For all types $\tau, \llbracket \star_{\tau} \rrbracket=\#_{\tau}$.

We define in addition a number of abbreviations:

LC1 $\exists u \phi \equiv \neg \forall u \neg \phi$

LC2 $[\phi \rightarrow \psi] \equiv[\neg \phi \vee \psi]$

LC3 $\alpha \neq \beta \equiv \neg \alpha=\beta$

LC4 $|\pi|=1 \equiv \exists x[\pi(x) \wedge \forall y[\pi(y) \rightarrow x=y]]$

LC5 $|\pi| \leq 1 \equiv \forall x[\pi(x) \rightarrow \forall y[\pi(y) \rightarrow x=y]]$

LC6 $\pi \subseteq \pi^{\prime} \equiv \forall x\left[\pi(x) \rightarrow \pi^{\prime}(x)\right]$

Finally, let us define some abbreviations for the type-shifting operations that we will use:

TS1 IOTA $\equiv \lambda P . \iota x P(x)$

$\mathrm{TS} 2 \mathrm{EX} \equiv \lambda P . \lambda Q \cdot \exists x[P(x) \wedge Q(x)]$

$\mathrm{TS} 3 \mathrm{R} \equiv \lambda P \cdot \lambda y \cdot \lambda x \cdot[P(x) \wedge \operatorname{POSS}(y)(x)]$

$\mathrm{TS} 4 \mathrm{OR} \equiv \lambda R \cdot \lambda v_{\langle e t, t\rangle} \cdot \lambda y \cdot v(\lambda z \cdot R(z)(y))$

\footnotetext{
45 The reader may worry that this logic is not sufficiently expressive since it is based on the Weak Kleene connectives. But with the help of the other unary operators in Table 4, the Strong Kleene connectives can be reconstructed, so this logic is just as expressive. A brute-force way of reconstructing Strong Kleene conjunction from Weak Kleene conjunction is as follows (where $\wedge_{W}$ stands for Weak Kleene conjunction and $\wedge_{S}$ stands for Strong Kleene conjunction):

$\left[\phi \wedge_{S} \psi\right] \equiv\left[A\left[\phi \wedge_{W} \psi\right] \wedge_{W} \partial\left[\neg A \phi \vee_{W} C \phi\right] \wedge_{W} \partial\left[\neg A \phi \vee_{W} C \phi\right] \wedge_{W} \partial\left[C \phi \vee_{W} C \psi\right]\right]$
} 


\section{A.2 English}

\section{A.2.1 Syntactic trees}

For the most part, our particular syntactic assumptions do not play a major role, because our semantic interpretation rules are type-driven. However, for concreteness, let us assume the following simple grammar, assuming traces and quantifying-in as implemented in Heim and Kratzer (1998).

Phrase structure rules.

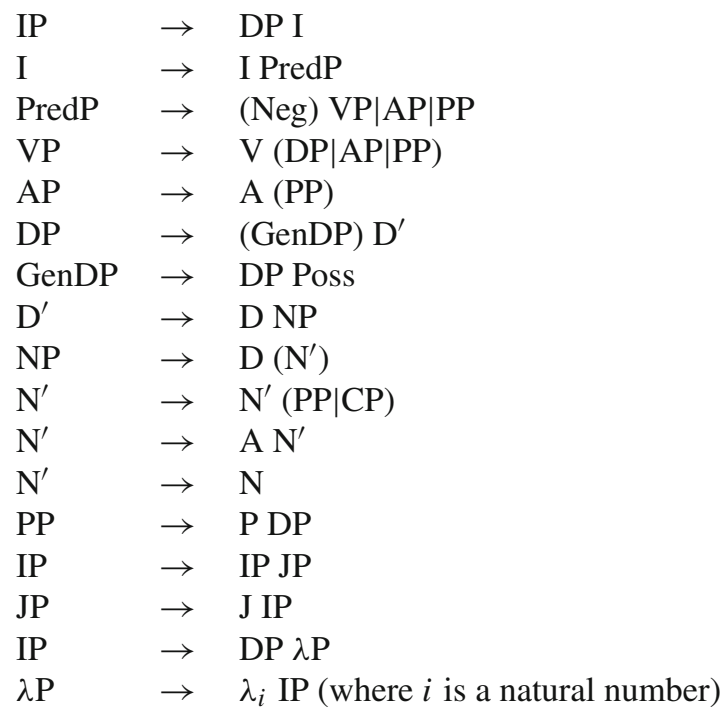

Lexical insertion rules.

$\mathrm{J} \quad$ : and, or

I : is, does, did

$\mathrm{V}$ : smoke, love, exist, give, see

Neg : not

A : only, female

$\mathrm{N}$ : talk, teacher, rabbit, grandmother

D : the, a, every, some, no

D : Scott, 'Waverley', Anna

D : $h e_{i}, s h e_{i} i t_{i}, t_{i}$

Poss : 's

$\mathrm{P} \quad$ : of, with, from

C : that

The subscript $i$ in the above stands for any natural number. The reader may have noticed that, among its many deficiencies, this grammar does not generate gave, only did give; all Vs are non-finite. 


\section{A.2.2 Translations}

For each tree $\chi$ we define a set of translations $\chi^{\prime}$ by induction on the translation relation $\rightsquigarrow$.

Basic expressions.

1. and $\rightsquigarrow \lambda p_{t} \cdot \lambda q_{t} .[p \wedge q]$

2. $o r \rightsquigarrow \lambda p_{t} . \lambda q_{t} .[p \vee q]$

3. not $\rightsquigarrow \lambda P . \lambda x \cdot \neg P(x)$

4. the $\rightsquigarrow \lambda P . \lambda x .[\partial(|P| \leq 1) \wedge P(x)]$

5. $a \rightsquigarrow \lambda P . P$

6. every $\rightsquigarrow \lambda P . \lambda Q . \forall x[P(x) \rightarrow Q(x)]$

7. $n o \rightsquigarrow \lambda P . \lambda Q . \forall x[P(x) \rightarrow \neg Q(x)]$

8. some $\rightsquigarrow \lambda P . \lambda Q . \exists x[P(x) \wedge Q(x)]$

9. Scott $\rightsquigarrow \mathrm{S}$

10. 'Waverley' $\rightsquigarrow \mathrm{W}$

11. Anna $\rightsquigarrow \mathrm{A}$

12. teacher $\rightsquigarrow \lambda x$. TEACHER $(x)$

13. talk $\rightsquigarrow \lambda x \cdot \operatorname{TALK}(x)$

14. horse $\rightsquigarrow \lambda x$. HORSE $(x)$

15. author $\rightsquigarrow \lambda y \cdot \lambda x$. AUTHOR $(y)(x)$

16. ' $s \rightsquigarrow \lambda R_{\langle e, e t\rangle} . R$

17. of $\rightsquigarrow \lambda x . x$

18. with $\rightsquigarrow \lambda y \cdot \lambda x \cdot \operatorname{WiTH}(y)(x)$

19. from $\rightsquigarrow \lambda y \cdot \lambda x \cdot \operatorname{FROM}(y)(x)$

20. only $\rightsquigarrow \lambda P . \lambda x .[\partial(P(x)) \wedge \forall y[x \neq y \rightarrow \neg P(y)]$

21. is/areldo/did $\rightsquigarrow \lambda P . P$

22. exist $\rightsquigarrow \lambda x . \operatorname{ACTUAL}(x)$

23. give $\rightsquigarrow \lambda y \cdot \lambda x \cdot \operatorname{GIVE}(y)(x)$

24. see $\rightsquigarrow \lambda y \cdot \lambda x \cdot \operatorname{SEE}(y)(x)$

Composition rules. Complex trees are translated using the following type-driven rules (this fragment might profitably be extended with suitably adapted versions of Beaver and Krahmer 2001 other composition rules):

\section{Functional Application}

If $\alpha \rightsquigarrow \alpha_{\langle\sigma, \tau\rangle}^{\prime}$ and $\beta \rightsquigarrow \beta_{\sigma}^{\prime}$, and $\gamma$ is an expression consisting of $\alpha$ and $\beta$, then:

$$
\gamma \rightsquigarrow \alpha^{\prime}\left(\beta^{\prime}\right)
$$

\section{Predicate Modification}

If $\alpha \rightsquigarrow \alpha_{\langle e, t\rangle}^{\prime}$ and $\beta \rightsquigarrow \beta_{\langle e, t\rangle}^{\prime}$, and $\gamma$ is an expression consisting of $\alpha$ and $\beta$, then:

$$
\gamma \rightsquigarrow \lambda u \cdot\left[\alpha^{\prime}(u) \wedge \beta^{\prime}(u)\right]
$$

where $u$ is a variable of type $e$ not free in $\alpha^{\prime}$ or $\beta^{\prime}$. 


\section{Predicate Abstraction}

If $\gamma$ is an expression of the form $\alpha_{i}$, where $i$ is a natural number and $\alpha$ is a relative pronoun or $\lambda$, and $\beta$, and $\beta \rightsquigarrow \beta^{\prime}$, then:

$$
\gamma \rightsquigarrow \lambda v_{i, e} \cdot \beta^{\prime}
$$

\section{Non-branching Nodes}

If $\alpha \rightsquigarrow \alpha^{\prime}$, and $\beta$ is an expression whose only daughter is $\alpha$, then $\beta \rightsquigarrow \alpha^{\prime}$.

\section{Pronouns and Traces}

If $\alpha$ is a trace or a pronoun, $\alpha_{i} \rightsquigarrow v_{i, e}$

\section{Shifting Rule}

If $\delta \in \Delta$ (where $\Delta$ is the set of shifting operations in the language), and $\delta$ is of type $\langle\sigma, \tau\rangle$, and $\alpha \rightsquigarrow \alpha_{\sigma}^{\prime}$, then:

$$
\alpha \rightsquigarrow \delta\left(\alpha^{\prime}\right)
$$

\section{A.2.3 Inventory of shifting operations $\Delta$}

$$
\Delta_{\text {English }}=\{\text { IOTA, EX, OR, R }\}
$$

\section{A.3 Semantic principles}

\section{Maximize Presupposition}

In a context $C$, lexical item $\alpha$ blocks $\beta$ in a derivation iff (i) $\alpha$ and $\beta$ are competitors, (ii) $\alpha$ presuppositionally dominates $\beta$, and (iii) replacing $\alpha$ by $\beta$ does not affect how $C$ would be updated. ${ }^{46}$

\section{Type Simplicity}

Given a choice between two type-shifting operations, a hearer should choose the one resulting in the simpler type and accommodate any associated presuppositions if they are consistent with the available evidence regarding what the speaker presupposes.

\section{A.4 Remarks on the logic}

\section{A.4.1 Quantification and presupposition}

We have followed Haug's (2013) semantics for the universal quantifier, which effectively implements an existential presupposition, as suggested by Beaver (1994). This has the ugly consequence that the universal quantifier is not the natural generalization of conjunction. The universal quantifier that would be the natural generalization of

\footnotetext{
46 See (72) and (74) in Sect. 2.6 for the definitions of presuppositional domination and update. We assume that if the speaker produces a sentence containing an expression $\alpha$, and there happens to be a high frequency lexical item $\beta$ which is classically equivalent to $\alpha$, then the speaker will also have considered producing the variant sentence with $\beta$ for $\alpha$.
} 
conjunction would be the following, since conjunction yields \# whenever one of the conjuncts is undefined:

$$
\llbracket \forall u \phi \rrbracket^{M, g}=\left\{\begin{array}{l}
\# \text { if for any } d \in D_{\tau}, \llbracket \phi \rrbracket^{M, g[u \rightarrow d]}=\# \\
\mathrm{~F} \text { if not, and there is a } d \in D_{\tau} \text { such that } \llbracket \phi \rrbracket^{M, g[u \rightarrow d]}=\mathrm{F} \\
\mathrm{T} \text { otherwise }
\end{array}\right.
$$

The problem with this is that it gives us a universal presupposition for all quantified sentences containing presuppositions. In particular, it predicts that Anna didn't give the only invited talk presupposes that everything in the domain of discourse is an invited talk.

The sacrifice of a tight connection between conjunction and universal quantification might not be a bad thing from a linguistic perspective: "Sweden cherishes its king and France cherishes its king" doesn't seem to have quite the same status as "every nation cherishes its king." The logical purists among our readers may, however, consider (136) the true universal quantifier in our logic, and consider how the one we defined above can be defined in terms of more elementary bits and pieces. For what it's worth, our universal quantifier is the natural generalization of a binary connective that yields undefined when both conjuncts are undefined and otherwise treats \# as F. This connective (call it o) can be defined as follows:

$[\phi \circ \psi] \equiv[\partial(C \phi \vee C \psi) \wedge A \phi \wedge A \psi]$

'It is presupposed that either $\phi$ or $\psi$ has a classical value and it is appropriate to assert $\phi$ and it is appropriate to assert $\psi$ '

This connective yields the undefined value only when both conjuncts are undefined; this is much like an existence presupposition.

Another more standard approach that we have opted not to take would involve a ranking of truth values $\mathrm{T}>\#>\mathrm{F}$ (Muskens 1995; Beaver and Krahmer 2001). On this approach, $\forall x \phi$ is defined as the lowest value that $\phi$ takes on for any value of $x$. This approach also makes some potentially counterintuitive predictions. Imagine a circumstance $w$ in which there are 10 nations which have a king and cherish him, one nation which has no king, and one nation which has a king but does not cherish him. Then "every nation cherishes its king", understood as $\forall x$ [NATION $(x) \rightarrow$ $\operatorname{CHERISH}(\iota y \operatorname{KING}(y)(x))(x)$ ], would be false in $w$, because there is one value of $x$ for which the universal comes out false, namely the nation that does not cherish its king. If, perhaps as the result of peace talks, the situation is changed so as to eliminate this ungrateful nation, the statement is undefined. Yet if one sees 'undefined' as 'nonsense', then intuitively, the source of the undefinedness is present under both scenarios. If it is undefined in one, then, one might think that it should be undefined in the other. The existential presupposition approach avoids this counterintuitive prediction.

Note further that our semantics implies that in a case like The mother of every girl waved to her, discussed by Mates (1973) and Glanzberg (2007), where a quantifier occurs within a description, an existential rather than a universal uniqueness presupposition is projected: that there is a girl with at most one mother. This prediction seems a bit too weak for this case. 


\section{A.4.2 Presuppositional properties}

Here we state two useful equivalences. If $\phi$ and $\psi$ are classical, then:

Quantifier Projection $\exists u[\partial \phi \wedge \psi] \equiv \exists u[\partial \phi] \wedge \exists u[\phi \wedge \psi]$

Negation Projection $\neg[\partial \phi \wedge \psi] \equiv[\partial \phi \wedge \neg \psi]$

Here, a formula $\phi$ is classical if $\llbracket \phi \rrbracket^{M, g} \in\{\mathrm{T}, \mathrm{F}\}$ for all $M, w, g$.

Proof of first property:

1. Let $A \equiv \exists u[\partial \phi \wedge \psi]$, and $B \equiv \exists u[\partial \phi] \wedge \exists u[\phi \wedge \psi]$.

2. Note that since $\psi$ is classical and conjunctions have defined truth values iff both conjuncts have defined values, $\partial \phi \wedge \psi$ has defined truth value iff $\partial \phi$ has defined truth value.

3. $\llbracket A \rrbracket^{M, w, g}=\#$ iff

$\llbracket \partial \phi \wedge \psi \rrbracket^{M, w, g[u \rightarrow d]}=\#$ for all $d \in D_{\tau}$ iff

$\llbracket \partial \phi \rrbracket^{M, w, g[u \rightarrow d]}=$ \# for all $d \in D_{\tau}$.

4. Thus $A$ and $B$ have the same undefinedness conditions.

5. $\llbracket A \rrbracket^{M, w, g}=\mathrm{T}$ iff for some $d \in D_{\tau}, \llbracket \partial \phi \rrbracket^{M, w, g[u \rightarrow d]}=\mathrm{T}$ and $\llbracket \psi \rrbracket^{M, w, g[u \rightarrow d]}=\mathrm{T}$. These two hold iff $\llbracket \phi \rrbracket^{M, w, g[u \rightarrow d]}=\mathrm{T}$ and $\llbracket \psi \rrbracket^{M, w, g[u \rightarrow d]}=\mathrm{T}$.

6. $\llbracket B \rrbracket^{M, w, g}=\mathrm{T}$ iff (i) for some $d \in D_{\tau}, \llbracket \phi \rrbracket^{M, w, g[u \rightarrow d]}=\mathrm{T}$ (from its first conjunct) and (ii) for some $d \in D_{\tau}, \llbracket \phi \rrbracket^{M, w, g[u \rightarrow d]}=\mathrm{T}$, and $\llbracket \psi \rrbracket^{M, w, g[u \rightarrow d]}=\mathrm{T}$ (from its second conjunct).

7. But since (ii) implies (i), it is clear that $\llbracket A \rrbracket^{M, w, g}=\mathrm{T}$ iff $\llbracket B \rrbracket^{M, w, g}=\mathrm{T}$.

8. Since $A$ and $B$ have the same undefinedness and truth conditions (and thus also the same falsity conditions), it follows that these formulae are equivalent, and thus the Quantifier Projection property holds.

Proof of the second property proceeds by inspection of the semantics for negation, conjunction, and the presupposition operator.

\section{References}

Aguilar-Guevara, A., \& Zwarts, J. (2010). Weak definites and reference to kinds. In Proceedings of SALT 20, eLanguage (pp. 179-196).

Barker, C. (1995). Possessive descriptions. Stanford: CSLI Publications.

Barker, C. (2004). Possessive weak definites. In Y. Kim, Y. Lander, \& B. H. Partee (Eds.), Possessives and beyond: Semantics and syntax (pp. 89-113). Amherst: GSLA Publications.

Barwise, J., \& Cooper, R. (1981). Generalized quantifiers and natural language. Linguistics and Philosophy, 4, 159-219.

Beaver, D. (1992). The kinematics of presupposition. In P. Dekker \& M. Stokhof (Eds.), Proceedings of the eighth Amsterdam colloquium (pp. 17-36). Amsterdam: ILLC, University of Amsterdam.

Beaver, D. (1994). When variables don't vary enough. In M. Harvey \& L. Santelmann (Eds.), Proceedings of SALT IV (pp. 35-60). Ithaca: Cornell University.

Beaver, D. I., \& Clark, B. Z. (2008). Sense and sensitivity: How focus determines meaning. Chichester: Wiley-Blackwell.

Beaver, D., \& Krahmer, E. (2001). A partial account of presupposition projection. Journal of Logic, Language and Information, 10, 147-182.

Beaver, D., \& Zeevat, H. (2007). Accommodation. In The Oxford handbook of linguistic interfaces (pp. 503-539). Oxford: Oxford University Press. 
Carlson, G. N., Sussman, R., Klein, N., \& Tannenhaus, M. (2006). Weak definite noun phrases. In C. Davis, A. R. Deal, \& Y. Zabal (Eds.), Proceedings of NELS 36 (pp. 179-196). Amherst: GSLA, University of Massachusetts.

Chierchia, G. (1998). Reference to kinds across languages. Natural Language Semantics, 6, 339-405.

Cooper, R. (1978). Variable binding and relative clauses. In F. Guenthner \& S. J. Schmidt (Eds.), Formal semantics and pragmatics for natural languages (pp. 131-170). Dordrecht: Reidel.

Cooper, R. (2013). Update conditions and intensionality in a type-theoretic approach to dialogue semantics. In R. Fernández \& A. Isard (Eds.), Proceedings of SemDial 2013, University of Amsterdam (pp. 15-24). http://www.illc.uva.nl/semdial/.

Coppock, E., \& Beaver, D. (2011). Sole sisters. In N. Ashton, A. Chereches, \& D. Lutz (Eds.), Proceedings of semantics and linguistic theory (SALT) 21, eLanguage (pp. 197-217). Newark: Rutgers University.

Coppock, E., \& Beaver, D. (2012a). Exclusivity, uniqueness, and definiteness. In C. Piñón (Ed.), Empirical Issues in Syntax and Semantics 9. Published online at http://www.cssp.cnrs.fr.

Coppock, E., \& Beaver, D. (2012b). Weak uniqueness: The only difference between definites and indefinites. In A. Chereches (Ed.), Proceedings of semantics and linguistic theory (SALT) 22 (pp. 527-544). Ithaca, NY: CLC Publications.

Coppock, E., \& Beaver, D. (2014). Principles of the exclusive muddle. Journal of Semantics, 31(3), 371-432.

Dayal, V. (2004). Number marking and (in)definiteness in kind terms. Linguistics and Philosophy, 27, $393-450$.

Donnellan, K. S. (1966). Reference and definite descriptions. The Philosophical Review, 75, 281-304.

Doron, E. (1983). Verbless predicates in Hebrew. PhD Thesis, University of Texas at Austin.

Elbourne, P. (2005). Situations and individuals. Cambridge: Cambridge University Press.

Elbourne, P. (2012). Definite descriptions. Oxford: Clarendon Press.

Fara, D. G. (2001). Descriptions as predicates. Philosophical Studies, 102, 1-42. (Originally published under the name "Delia Graff").

Fara, D. G. (2015). Names are predicates. Philosophical Review, 124(1), 59-117.

Frege, G. (1892). [reprinted 1948]). Sense and reference. The Philosophical Review, 57(3), 209-230.

Gendler Szabó, Z. (2000). Descriptions and uniqueness. Philosophical Studies, 101, 29-57.

Geurts, B. (1999). Presuppositions and pronouns. Oxford: Elsevier.

Geurts, B., \& van der Sandt, R. (2004). Interpreting focus. Theoretical Linguistics, 30(1), 1-44.

Glanzberg, M. (2007). Definite descriptions and quantifier scope: Some Mates cases reconsidered. European Journal of Analytic Philosophy, 3(2), 133-158.

Grice, H. P. (1981). Presupposition and conversational implicature. In P. Cole (Ed.), Radical pragmatics (pp. 183-198). New York: Academic Press.

Haug, D. (2013). Partial dynamic semantics for anaphora: Compositionality without syntactic coindexation. Journal of Semantics (online first).

Heim, I. (1982). The semantics of definite and indefinite noun phrases. PhD Thesis, University of Massachusetts at Amherst.

Heim, I. (1983). On the projection problem for presuppositions. In D. Flickinger, M. Barlow, \& M. Westcoat (Eds.), Proceedings of the second West Coast conference on formal linguistics (pp. 114-125). Stanford, CA: Stanford University Press.

Heim, I. (1991). Artikel und Definitheit. In A. von Stechow \& D. Wunderlich (Eds.), Semantik: Ein internationales Handbuch der zeitgenössischen Forschung (pp. 487-535). Berlin: Mouton de Gruyter.

Heim, I., \& Kratzer, A. (1998). Semantics in generative grammar. Oxford: Blackwell.

Hendriks H (1993). Studied flexibility: Categories and types in syntax and semantics. PhD Thesis, Universiteit van Amsterdam.

Hoeksema, J. (1988). The semantics of non-boolean and. Journal of Semantics, 6, 19-40.

Horn, L., \& Abbott, B. (2002). <the, a>: (In)definiteness and implicature. In W. Kabasenche, M. O'Rourke, \& M. Slater (Eds.), Reference and referring (pp. 325-355). Cambridge, Mass.: MIT Press.

Isaacs, J., \& Rawlins, K. (2008). Conditional questions. Journal of Semantics, 25(3), 269-319.

Kadmon, N. (1987). On unique and non-unique reference and asymmetric quantification. $\mathrm{PhD}$ Thesis, University of Massachusetts at Amherst.

Kamp, H. (2001). The importance of presupposition. In C. Rohrer, A. Roßdeutscher, \& H. Kamp (Eds.), Linguistic form and its computation (pp. 207-254). Stanford, CA: CSLI Publications.

Kaplan, D. (1977). Demonstratives: An essay on the semantics, logic, metaphysics, and epistemology of demonstratives and other indexicals. In J. P. Almog \& H. Wettstein (Eds.), Themes from Kaplan (pp. 267-298). Oxford: Oxford University Press. 
Karttunen, L. (1974). Presuppositions and linguistic context. Theoretical Linguistics, 1, 181-194.

Karttunen, L. (1976). Discourse referents. In J. D. McCawley (Ed.), Notes from the linguistic underground. Syntax and Semantics (Vol. 7, pp. 363-385). New York: Academic Press.

Kripke, S. A. (2011). Philosophical troubles: Collected papers. Oxford: Oxford University Press.

Landman, F. (2004). Indefinites and the type of sets. Malden, MA: Blackwell.

Lasersohn, P. (1993). Existence presuppositions and background knowledge. Journal of Semantics, 10, $113-122$.

Löbner, S. (1985). Definites. Journal of Semantics, 4, 279-326.

Löbner, S. (2011). Concept types and determination. Journal of Semantics, 28, 279-333.

Mates, B. (1973). Descriptions and reference. Foundations of Language, 10, 409-418.

Matushansky, O. (2008). On the linguistic complexity of proper names. Linguistics and Philosophy, 21, 573-627.

McNally, L. (1992). An interpretation for the English existential construction. PhD Thesis, UC Santa Cruz.

McNally, L. (1998). Existential sentences without existential quantification. Linguistics and Philosophy, $21,353-392$.

Moltmann, F. (1997). Intensional verbs and quantifiers. Natural Language Semantics, 5, 1-52.

Montague, R. (1974). The proper treatment of quantification in ordinary English. In R. H. Thomason (Ed.), Formal philosophy (pp. 247-270). New Haven: Yale University Press.

Muskens, R. (1995). Meaning and partiality. Stanford, CA: CSLI Publications.

Muskens, R. (1996). Combining Montague semantics and discourse representation. Linguistics and Philosophy, 19, 143-186.

Neale, S. (1990). Descriptions. Cambridge, MA: MIT Press.

Nelson, M. (2012). Existence. In E. Zalta (Ed.), The Stanford encyclopedia of philosophy. http://plato. stanford.edu/archives/win2012/entries/existence/.

Oliver, A., \& Smiley, T. (2013). Plural logic. Oxford: Oxford University Press.

Partee, B. H. (1986). Noun phrase interpretation and type-shifting principles. In J. Groenendijk, D. de Jongh, \& M. Stokhof (Eds.), Studies in discourse representation theory and the theory of generalized quantifiers (pp. 115-143). Dordrecht: Foris.

Partee, B., \& Borschev, V. (2003). Genitives, relational nouns, and argument-modifier ambiguity. In E. Lang, C. Maienborn, \& C. Fabricius-Hansen (Eds.), Modifying adjuncts (pp. 67-112). Berlin: Mouton de Gruyter.

Percus, O. (2006). Antipresuppositions. In A. Ueyama (Ed.), Theoretical and empirical studies of reference and anaphora: Toward the establishment of generative grammar as an empirical science (pp. 52-73). Tokyo: Japan Society for the Promotion of Science.

Peters, S. (1979). A truth-conditional formulation of Karttunen's account of presupposition. Synthese, 40(2), 301-316.

Peters, S., \& Westerståhl, D. (2013). The semantics of possessives. Language, 89(4), 713-759.

Poesio, M. (1994). Weak definites. In M. Harvey \& L. Santelmann (Eds.), Proceedings of the fourth conference on semantics and linguistic theory. Ithaca: CLC Publications.

Rawlins, K. (2005). Possessive definites and the definite article. UCSC Qualifying Paper.

Rawlins, K. (2006). Possessive antecedents to donkey pronouns. In D. Baumer, D. Montero, \& M. Scanlon (Eds.), Proceedings of the 25th West Coast conference on formal linguistics (pp. 337-345). Somerville, MA: Cascadilla Press.

Reinhart, T. (1997). Quantifier scope: How labor is divided between QR and choice functions. Linguistics and Philosophy, 20, 335-397.

Roberts, C. (1989). Modal subordination and pronominal anaphora in discourse. Linguistics and Philosophy, $12,683-721$.

Roberts, C. (1996). Information structure in discourse: Towards an integrated formal theory of pragmatics. In J. H. Yoon \& A. Kathol (Eds.), OSU Working Papers in Linguistics 49: Papers in Semantics (pp. 91-136). Columbus: The Ohio State University.

Russell, B. (1905). On denoting. Mind, 14, 479-493.

Schlenker, P. (2012). Maximize Presupposition and Gricean reasoning. Natural Language Semantics, 20(4), $391-429$.

Schoubye, A. J. (2009). Descriptions, truth value intuitions, and questions. Linguistics and Philosophy, $32(6), 583-617$.

Schoubye, A. J. (2014). Type-ambiguous names. Ms., University of Edinburgh.

Schwarz, F. (2012). How weak and how definite are weak definites? Ms., University of Pennsylvania. 
Stalnaker, R. (1978). Assertion. In P. Cole (Ed.), Syntax and semantics (Vol. 9, pp. 315-332). New York: Academic Press.

Strawson, P. F. (1950). On referring. Mind, 59(235), 320-344.

Strawson, P. (1964). Identifying reference and truth-values. Theoria, 30(2), 96-118.

Thomason, R. (1990). Accommodation, meaning, and implicature: Interdisciplinary foundations for pragmatics. In P. Cohen, J. Morgan, \& M. Pollack (Eds.), Intentions in communication (pp. 326-363). Cambridge, MA: MIT Press.

van der Sandt, R. A. (1992). Presupposition projection as anaphora resolution. Journal of Semantics, 9 , 333-377.

Vikner, C., \& Jensen, P. A. (2002). A semantic analysis of the English genitive: Interaction of lexical and formal semantics. Studia Linguistica, 56, 191-226.

von Fintel, K. (2004). Would you believe it? The king of France is back! (Presuppositions and truth-value intuitions). In A. Bezuidenhout \& M. Reimer (Eds.), Descriptions and beyond (pp. 315-342). Oxford: Oxford University Press.

von Heusinger, K. (1997). Definite descriptions and choice functions. Logic, Language and Computation, 5, 61-91.

Wang, L., \& McCready, E. (2005). Testing predicative definite descriptions. Ms., National Chung Cheng University and Osaka University.

Winter, Y. (2001). Flexibility principles in Boolean semantics. Cambridge, MA: MIT Press.

Zimmermann, T. E. (1993). On the proper treatment of opacity in certain verbs. Natural Language Semantics, 1(2), 149-179. 